\title{
ARTICLE \\ Role of RGS12 in the differential regulation of kappa opioid receptor-dependent signaling and behavior
}

\author{
Joshua D. Gross ${ }^{1,2,3}$, Shane W. Kaski ${ }^{1,2,3}$, Karl T. Schmidt ${ }^{4}$, Elizabeth S. Cogan ${ }^{4}$, Kristen M. Boyt ${ }^{4}$, Kim Wix ${ }^{1}$, Adam B. Schroer ${ }^{1}$, \\ Zoe A. McElligott ${ }^{4}$, David P. Siderovski ${ }^{1,2}$ and Vincent Setola ${ }^{1,2,3}$
}

\begin{abstract}
Kappa opioid receptor (KOR) agonists show promise in ameliorating disorders, such as addiction and chronic pain, but are limited by dysphoric and aversive side effects. Clinically beneficial effects of KOR agonists (e.g., analgesia) are predominantly mediated by heterotrimeric $\mathrm{G}$ protein signaling, whereas $\beta$-arrestin signaling is considered central to their detrimental side effects (e.g., dysphoria/aversion). Here we show that Regulator of $G$ protein Signaling-12 (RGS12), via independent signaling mechanisms, simultaneously attenuates $\mathrm{G}$ protein signaling and augments $\beta$-arrestin signaling downstream of KOR, exhibiting considerable selectivity in its actions for KOR over other opioid receptors. We previously reported that RGS12-null mice exhibit increased dopamine transporter-mediated dopamine (DA) uptake in the ventral (vSTR), but not dorsal striatum (dSTR), as well as reduced psychostimulant-induced hyperlocomotion; in the current study, we found that these phenotypes are reversed following KOR antagonism. Fast-scan cyclic voltammetry studies of dopamine (DA) release and reuptake suggest that striatal disruptions to KORdependent DAergic neurotransmission in RGS12-null mice are restricted to the nucleus accumbens. In both ventral striatal tissue and transfected cells, RGS12 and KOR are seen to interact within a protein complex. Ventral striatal-specific increases in KOR levels and KOR-induced G protein activation are seen in RGS12-null mice, as well as enhanced sensitivity to KOR agonist-induced hypolocomotion and analgesia-G protein signaling-dependent behaviors; a ventral striatal-specific increase in KOR levels was also observed in $\beta$-arrestin-2-deficient mice, highlighting the importance of $\beta$-arrestin signaling to establishing steady-state KOR levels in this particular brain region. Conversely, RGS12-null mice exhibited attenuated KOR-induced conditioned place aversion (considered a $\beta$-arrestin signaling-dependent behavior), consistent with the augmented KOR-mediated $\beta$-arrestin signaling seen upon RGS12 over-expression. Collectively, our findings highlight a role for RGS12 as a novel, differential regulator of both G proteindependent and -independent signaling downstream of KOR activation.
\end{abstract}

Neuropsychopharmacology (2019) 44:1728-1741; https://doi.org/10.1038/s41386-019-0423-7

\section{INTRODUCTION}

KOR is highly expressed in mood- and pain-related CNS regions and is involved in such pathologies as addiction, depression, anxiety, and chronic pain [1, 2]. During stress, KOR activation by endogenous dynorphins results in analgesia, depressive / anxietylike behaviors, and altered drug reward [2-6]. KOR antagonists have shown promise in preclinical models of stress-related psychiatric diseases including addiction $[7,8]$. In contrast, acute administration of KOR agonists has been shown to exert utility specifically in reducing pain and drug reward-behavioral outcomes particularly relevant to the current United States opioid epidemic [9-12]. However, the advantageous effects of KOR agonists are limited by dysphoric side-effects [2, 4, 13]. Behaviors produced by KOR agonists depend upon which signaling cascade (s) is/are activated [14-17]-an example of biased agonism (a.k.a. functional selectivity) $[18,19]$. Agonists induce KOR conformational change [20], driving $G$ protein dissociation [21]. Freed $G$ protein subunits then induce biological responses, including CAMP reduction, potassium channel activation, and inhibition of calcium influx [22-25]. KOR activation also recruits GPCR kinases (GRKs) and $\beta$-arrestin to trigger desensitization, internalization, and activation of other pathways $[26,27]$. Pharmacological or genetic inhibition of the KOR-stimulated $\beta$-arrestin signaling pathway abolishes KOR agonist-induced conditioned place aversion (CPA) - a metric of dysphoria $[14,28]$. Thus, KOR-induced CPA is considered $\beta$-arrestindependent. Conversely, KOR-mediated analgesia is considered G protein-dependent and $\beta$-arrestin-independent $[7,16,29,30]$.

GPCR signaling is tightly controlled by Regulators of $G$ protein Signaling, which contain an RGS domain [31], serving as a GTPaseaccelerating protein (GAP) for Ga [32] and thereby inhibiting $G$ protein signaling [33]. Loss of RGS expression increases GPCR sensitivity to agonist stimulation (e.g., [34, 35]). Some RGS proteins contain additional domains that modulate signaling independent of GAP activity [36, 37]. For example, RGS12 contains a PDZ domain, a phosphotyrosine binding (PTB) domain, Ras binding domains (RBDs) [38], and a GoLoco motif, which sequesters inactive Ga.GDP and thereby serves as a GDP dissociation inhibitor (GDI) [39].

We recently found [40] that RGS12 is enriched in the ventral striatum (vSTR) of the mesolimbic dopamine (DA) system which

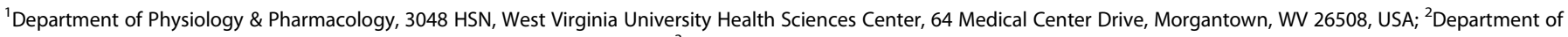

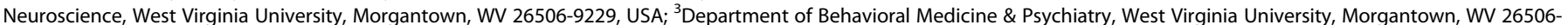
9229, USA and ${ }^{4}$ Bowles Center for Alcohol Studies and Department of Psychiatry, University of North Carolina at Chapel Hill, Chapel Hill, NC 27599, USA Correspondence: David P. Siderovski (dsiderovski@gmail.com) 
contributes to reward and affect [41, 42]. RGS12 loss reduces psychostimulant-induced hyperlocomotion and elevates dopamine transporter (DAT) expression and DA uptake in the vSTR, but not dorsal striatum (dSTR) [40]. We hypothesized that RGS12 loss could elevate vSTR KOR activity/sensitivity, as KOR is highly expressed in the mesolimbic DA system and enriched on presynaptic terminals of the nucleus accumbens (NAc) (terminals that originate from ventral tegmental area (VTA) DAergic projections $[1,43])$. Mesolimbic KOR activation reduces extracellular DA-an action proposed to underlie dysphoric effects $[44,45]$. KOR-mediated DA decrease occurs by inhibition of exocytotic DA release $[46,47]$ and increased DAT-mediated DA reuptake via $\mathrm{Ga}_{\mathrm{i} / \mathrm{o}}$ and MAPK-dependent signaling $[48,49]$. Here, we examined whether augmented vSTR DA uptake and reduced psychostimulant-induced hyperlocomotion in RGS12null mouse strains [40] results from enhanced KOR action, given that RGS12 is an established inhibitor of $\mathrm{Ga}_{\mathrm{i} / \mathrm{o}}$ signaling [32]. Our investigation revealed that RGS12 more robustly affects KOR-mediated signaling than it does other opioid receptors, RGS12 differentially modulates G protein-dependent versus independent KOR signaling, and RGS12 loss differentially affects KOR-mediated behaviors, likely contingent upon which KORinitiated signaling cascade is required to elicit the particular behavioral outcome.

\section{MATERIALS AND METHODS}

Drugs and radioligands

The opioid receptor agonists U50,488 hydrochloride (Cat. no. 0495), DAMGO (Cat. no. 1171), and DADLE (Cat. no. 3790) were purchased from Tocris Bioscience (Minneapolis, MN). For all in vitro experiments with opioid receptor agonists, $10 \mathrm{mM}$ stocks were prepared with dimethyl sulfoxide (DMSO), then diluted to the appropriate final working concentrations in assay buffer. The KOR antagonist nor-Binaltorphimine dihydrochloride (nor-BNI; Cat. no. 0347) was also purchased from Tocris Bioscience, and was dissolved in sterile $0.9 \%$ sodium chloride (saline) for all experiments. D-Amphetamine hemisulfate salt and morphine sulfate salt pentahydrate were both purchased from Sigma Aldrich (St. Louis, MO) and dissolved in sterile saline for all experiments. For all animal experiments, drugs were administered intraperitoneally (ip). $\left[{ }^{3} \mathrm{H}\right]$ Dihydroxyphenylethylamine $\left(\left[{ }^{3} \mathrm{H}\right]\right.$ dopamine; Cat. no. NET673250UC), $\left[{ }^{3} \mathrm{H}\right]$ WIN35428 (Cat. no. NET1033250UC), and $\left[{ }^{3} \mathrm{H}\right]$ U-69,593 (Cat. no. NET952250UC) were purchased from PerkinElmer (Waltham, WA).

\section{Subjects}

Rgs $12^{\Delta 5-8 / \Delta 5-8}$ mice (a.k.a. Rgs12-/- or RGS12-null) [40] and wildtype $\left(\operatorname{Rgs} 12^{+/+}\right)$littermates, both C57BL/6J and of both sexes, were housed under conventional lighting ( $12 \mathrm{~h}$ light $/ 12 \mathrm{~h}$ dark), humidity, and temperature, with food and water ad libitum. Behaviors were tested within the light cycle. All mice used were 8-12 weeks of age. Experiments were in accordance with WVU Animal Care and Use Committee and NIH guidelines.

Synaptosomal $\left[{ }^{3} \mathrm{H}\right] \mathrm{DA}$ uptake

Synaptosomal $\left[{ }^{3} \mathrm{H}\right] \mathrm{DA}$ uptake was performed as described [40], with modifications described in Supplementary Methods.

\section{Locomotor activity}

AMPH-induced locomotor activity was measured as described [40] with modifications denoted in Supplementary Methods.

Fast-scan cyclic voltammetry (FSCV)

RGS12-null and wildtype littermates were injected with $10 \mathrm{mg} / \mathrm{kg}$ nor-BNI or saline (i.p.). $24 \mathrm{~h}$ later, brain slices were prepared and FSCV performed as described [50], with modifications detailed in Supplementary Methods.
Radioligand binding assays

$\left.{ }^{3} H\right]$ WIN35428 binding to DAT. DAT binding sites were quantified as described [40], with modifications detailed in Supplementary Methods.

$\left.{ }^{3} \mathrm{H}\right] U 69,593$ binding to KOR and ${ }^{35}$ S]GTPYS incorporation by KOR activation. KOR saturation binding and GTPYS incorporation assays were performed as described [51], with modifications detailed in Supplementary Methods.

\section{Co-immunoprecipitations}

Co-immunoprecipitations (co-IPs) from brain tissue were performed with the Pierce co-IP Kit (Waltham, MA) according to manufacturer's instructions, with modifications described in Supplementary Methods. Co-IP analyses in HEK293T cells were performed with the Pierce HA-Tag IP/Co-IP Kit according to manufacturer's instructions, with modifications detailed in Supplementary Methods.

cAMP inhibition

HEK293T cells were transfected via $\mathrm{CaPO}_{4}$ [52] with GloSensor-22F CAMP biosensor (Promega) and HA-tagged opioid receptor (3XHAhKOR, 3XHA-hMOR, or 3XHA-hDOR; www.cdna.org), with or without wildtype human RGS12, RGS domain loss-of-function RGS12 (Rgs12 $\left.{ }^{\mathrm{ET} 40 K}\right)$, or GoLoco motif loss-of-function RGS12 $\left(\operatorname{Rgs} 12^{R 1206 F}\right)$. Additional procedures are detailed in Supplementary Methods.

\section{$\beta$-arrestin recruitment}

Agonist-induced $\beta$-arrestin recruitment was determined using "Tango" assay [53, 54]. HTLA cells expressing $\beta$-arrestin-TEV protease fusion and tetracycline transactivator-driven luciferase reporter [53] were transfected via $\mathrm{CaPO}_{4}$ [52] with opioid receptorTango vectors (FLAG-KOR-Tango, FLAG-MOR-Tango, or FLAG-DORTango; contributed to Addgene by Dr. Bryan Roth) with or without WT hRGS12, Rgs $12^{E 740 K}$, or Rgs $12^{R 1206 F}$ vectors. Additional procedures are detailed in Supplementary Methods.

Hot plate analgesia and conditioned place aversion (CPA) tests To detect sensitivity to painful stimuli, the hot plate test of nociception was performed as previously described [55] with modifications detailed in Supplementary Information. CPA was performed as described [3] with modifications denoted in Supplemental Methods.

\section{RESULTS}

vSTR DAT dysfunction in RGS12-null mice is KOR-dependent Rgs12 mRNA is detected in multiple Oprk1-expressing neuronal populations in the mouse brain (Fig. S1), including the VTA and substantia nigra pars compacta (SNc), the anatomical loci of DAergic projection neurons; within the striatum, RGS12 protein is seen [40] to be particularly enriched within the ventral striatum. To evaluate whether increased KOR activity is responsible for elevated DAT-mediated DA uptake observed [40] in the vSTR of RGS12-null mice, $\left[{ }^{3} \mathrm{H}\right] \mathrm{DA}$ uptake by vSTR synaptosomes was measured following systemic pretreatment with the KOR-selective antagonist nor-BNI (Fig. 1a). Omnibus analyses revealed an effect of genotype, antagonist treatment, and a genotype $\times$ treatment interaction (genotype, $F(1,9)=13.5, p=0.005$; treatment, $F(1,9)=$ $13.4, \mathrm{p}=0.005$; interaction, $F(1,9)=7.0, p=0.026$ ). Synaptosomes from saline-pretreated RGS12-null mice exhibited increased DATmediated $\left[{ }^{3} \mathrm{H}\right] \mathrm{DA}$ uptake compared with wildtype mice $(p=0.001)$ (Fig. 1a). nor-BNI pretreatment $(10 \mathrm{mg} / \mathrm{kg}$, ip) reversed this effect $(p=0.002)$; nor-BNI pretreatment did not affect $\left[{ }^{3} \mathrm{H}\right] \mathrm{DA}$ uptake in wildtype controls $(p=0.768)$. All data from $\left[{ }^{3} \mathrm{H}\right] \mathrm{DA}$ uptake analyses are the mean \pm SEM and analyzed by two-way ANOVA followed by Sidak's post hoc test ( $n=4-8$ mice/group). 
A $\begin{aligned} R g s 12^{+/+} \\ R g s 12^{-/}\end{aligned}$

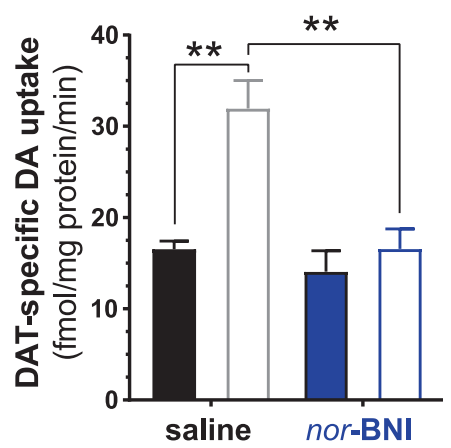

D DA release (NAc core)
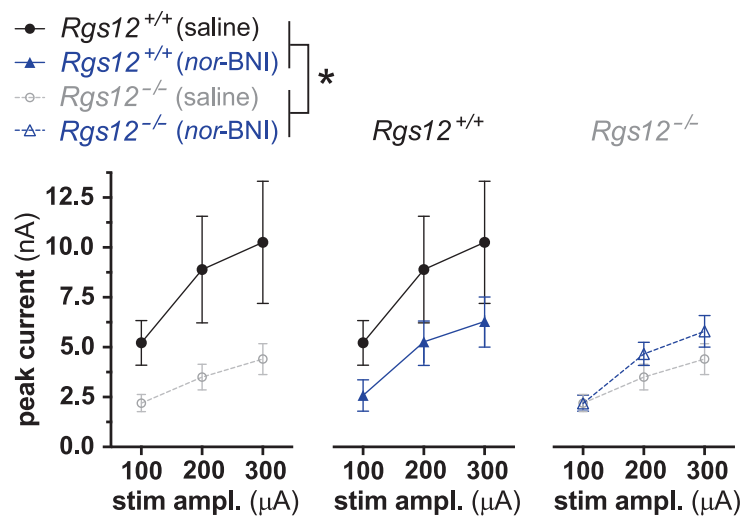

$\mathbf{F}$

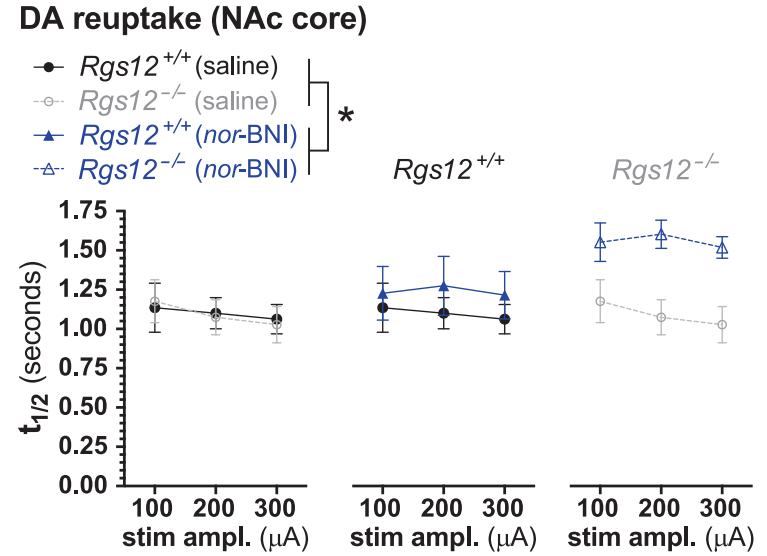

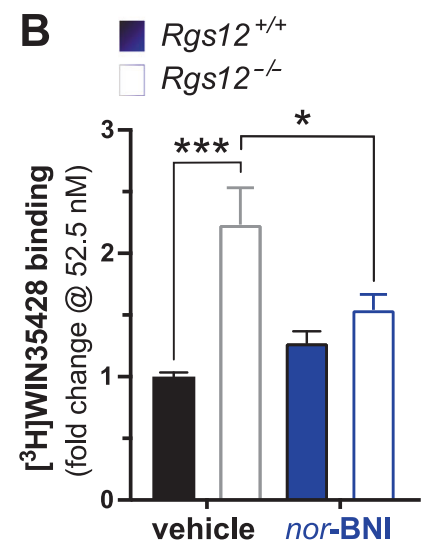

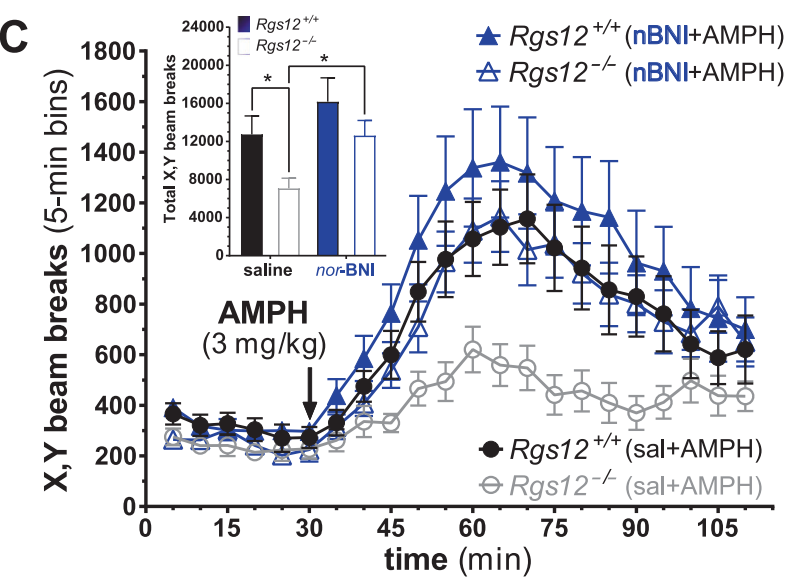

E DA release (NAc shell)

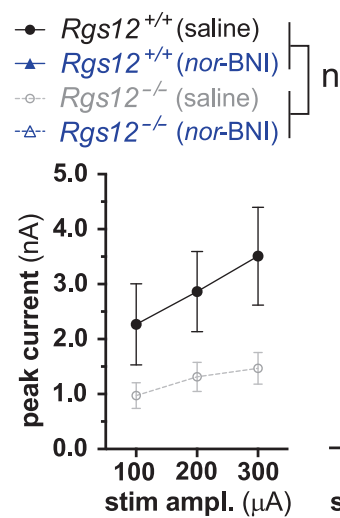

omnibus: stim X genotype $X$ nor-BNI $R_{X}$ $p=0.089$

G

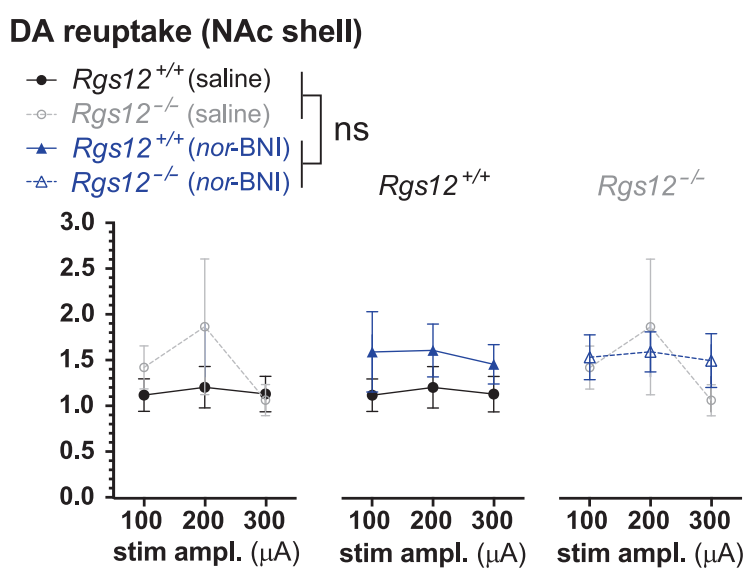

Fig. 1 Ventral striatal DAT dysfunction in RGS12-null mice is KOR-dependent. a Uptake of $\left.{ }^{3} \mathrm{H}\right]$ dopamine $(8 \mathrm{nM})$ and $\mathbf{b}$ the number of DAT binding sites are increased in vSTR synaptosomes derived from RGS12-null (Rgs $12^{-1-}$ ) mice vs WT (Rgs $12^{+/+}$) littermate controls; this increase is lost upon prior administration to the mice of the KOR-selective antagonist nor-BNI. Mice were administered vehicle (saline) or nor-BNI $(10 \mathrm{mg} / \mathrm{kg}$, ip) $24 \mathrm{~h}$ (a) or over 14 days (b) prior to sacrifice and synaptosome or membrane preparation, respectively. Non-specific binding was determined in the presence of $10 \mu \mathrm{M}$ GBR12935 (a selective DA reuptake inhibitor). Data are the mean \pm SEM and tested by two-way ANOVA with Sidak's post hoc test $\left(n=4-8\right.$ mice) $\left({ }^{*} p<0.05 ;{ }^{* *} p<0.01 ;{ }^{* * *} p<0.001\right)$. c Suppression of AMPH-induced hyperlocomotion by RGS12-null mice is reversed upon prior administration of nor-BNI. AMPH ( $3 \mathrm{mg} / \mathrm{kg}$, ip)-induced changes to locomotion behavior are shown in RGS12-null mice (open symbols) and WT littermate controls (closed symbols) following $30 \mathrm{~min}$ acclimation to activity chambers. Mice were treated with either vehicle (saline; circles) or nor-BNI $(10 \mathrm{mg} / \mathrm{kg}$ delivered ip; triangles) $24 \mathrm{~h}$ prior to the experiment. Data are the mean \pm SEM $(n=10-13$ mice per group). c (inset) Total locomotion (over $80 \mathrm{~min}$ ) by RGS12-null mice and WT littermate controls (derived from data in panel c) treated with saline or nor-BNI following injection of AMPH (3 mg/kg, ip). Data are the mean \pm SEM and tested by two-way ANOVA with Sidak's post hoc test $\left(n=10-13\right.$ mice per group) $\left({ }^{*} p<0.05\right)$. d Electrically-stimulated DA release (peak DA current, nA) is attenuated in the NAc core of RGS12null mice. e Electrically-stimulated DA release in the NAc shell. RGS12-null mice exhibit a trend towards altered nor-BNI-dependent DA release at select stimulation amplitudes (stimulation $\times$ genotype $\times$ antagonist treatment interaction). $f$ nor-BNI treatment reduces DA reuptake ( $t_{1 / 2}$ ) in RGS12-null, but not wildtype, mice. g Baseline and nor-BNI-dependent DA reuptake in the NAc shell is not altered in RGS12-null mice relative to wildtype mice. All FSCV data are mean \pm SEM $(n=6-11$ mice per group) and were analyzed by general linear mixed model ANOVA $\left({ }^{*} p<0.05\right)$ 
To test whether increased DAT binding sites in the VSTR of RGS12-null mice [40] was due to increased KOR expression/ sensitivity, we systemically pretreated RGS12-null and wildtype mice with nor-BNI (10 mg/kg, ip) or saline over 14 days and assessed $\left[{ }^{3} \mathrm{H}\right]$ WIN35428 binding to DAT (Fig. 1b). Omnibus analyses revealed an effect of genotype and a genotype $\times$ antagonist treatment interaction (genotype, $F(1,16)=19.5, p<0.001$; treatment $\times$ genotype interaction, $F(1,16)=8.0, p=0.011)$. Multiple comparisons analysis showed that saline-treated RGS12-null mice display increased $\left[{ }^{3} \mathrm{H}\right]$ WIN35428 binding to DAT relative to saline-treated wildtype mice $(p<0.001)$. Prolonged nor-BNI pretreatment reversed this effect $(p=0.048)$ to levels comparable to saline-treated wildtype mice $(p=0.149)$. nor-BNI treatment did not significantly affect DAT binding in wildtype mice $(p=0.673)$. All data from DAT binding analyses are the mean \pm SEM and analyzed by two-way ANOVA followed by Sidak's post hoc test ( $n=6$ mice/group).

Augmented DA uptake and DAT binding sites in RGS12-null mice were previously correlated with decreased hyperlocomotor response to the DA-dependent psychostimulant d-amphetamine (AMPH) [40]. To assess whether this blunted hyperlocomotion is due to increased KOR activity, RGS12-null mice were pretreated with nor-BNI $(10 \mathrm{mg} / \mathrm{kg}$, ip) $24 \mathrm{~h}$ prior to AMPH treatment. Omnibus analyses revealed an effect of genotype and antagonist treatment (genotype, $F(1,44)=7.5, p=0.009$; treatment, $F(1,44)=$ 7.0, $p=0.011)$. Attenuated AMPH-induced hyperlocomotion in RGS12-null mice $(p=0.039)$ was reversed following nor-BNI pretreatment ( $p=0.045)$ (Fig. 1c); in contrast, nor-BNI pretreatment did not affect $\mathrm{AMPH}$-induced hyperlocomotion of wildtype mice $(p=0.305)$. Hyperlocomotion data are the mean \pm SEM and analyzed by two-way ANOVA followed by a Sidak's post hoc test ( $n=10-13$ mice/group).

FSCV analyses of DA release and reuptake revealed significant effects of genotype and nor-BNI treatment within the NAc core, but not the NAc shell nor dSTR, in mice lacking RGS12 expression (Figs. $1 \mathrm{~d}-\mathrm{g}$ and Fig. S2). Examining peak DA release in the NAc core, we found significant main effects of stimulation amplitude $(F(62,2)=34.439, p<0.001)$ and genotype $(F(1,31)=4.875, p=$ $0.035)$, and a non-significant genotype $\times$ antagonist treatment interaction $(F(1,31)=3.206, p=0.083)$ (Fig. 1d). Furthermore, a significant main effect of antagonist treatment $(F(1,31)=6.089$, $p=0.019$ ) was seen on DA reuptake dynamics (Fig. 1f) as measured by $t_{1 / 2}$ [56]. Within the NAc shell (Fig. 1e), a significant main effect of stimulation amplitude was observed $(F(1.4,43.3)=$ 38.2, $p<0.0001)$, as well as a non-significant stimulation $\times$ genotype $\times$ antagonist treatment interaction $(F(2,62)=2.5, p=$ 0.089); however, there was no significant effect of genotype, antagonist treatment, or genotype $\times$ treatment interaction $(p>$ $0.05)$ regarding peak DA concentration. In the dSTR, we observed only an effect of stimulation amplitude $(F(1.2,38.3)=2, p<0.0001)$ and no effect of genotype, antagonist treatment, nor any interaction $(p>0.05)$ (Fig. S2A). There were no significant effects, in the NAc shell or the dSTR, on $t_{1 / 2}$ measures of DA reuptake $(p>$ $0.05)$ (Shell: Fig. 1g; dSTR: Fig. S2B). All data are mean \pm SEM and were analyzed by general linear mixed model with stimulation amplitude as a repeated factor and genotype and antagonist treatment as between-subject factors ( $n=6-11$ mice/group). It is important to note that electrical stimulation of striatal brain slices during FSCV also recruits local microcircuitry, including cholinergic interneurons, which can strongly influence DA release magnitude via acetylcholine release and subsequent activation of nicotinic cholinergic receptors expressed on DA terminals [57, 58]. Given high Rgs12 expression in ChAT+ (cholinergic) interneurons, yet relatively low expression of KOR in these neurons (e.g., Fig. S1C), it is possible that the KOR-independent reductions in accumbal DA release seen in RGS12-null mice may be due, in part, to RGS12 loss within ChAT+ striatal interneurons. Future studies will be required to parse out the relative contributions of this specific interneuron population.
RGS12 forms a protein complex with KOR in brain tissue and transfected cells

Endogenous KOR co-immunoprecipitates with endogenous RGS12 in vSTR tissue from wildtype mice (Fig. 2). KOR immunoreactivity was absent in immunoprecipitated samples from RGS12-null vSTR (Fig. 2a), suggesting that KOR immunoreactivity from the wildtype mouse vSTR sample was not due to non-specific KOR binding. Consistent with this finding from vSTR (Fig. 2a), we found robust RGS12 immunoreactivity in immunoprecipitates of HA-tagged KOR expressed in transfected HEK293T cells (Fig. 2b). Notably, co-expression of RGS12 with the mu opioid receptor (3XHA-MOR) resulted in only a weak, non-specific signal (relative to RGS12 alone-transfected cells; Fig. 2b), supporting the notion of a selective interaction of RGS12 with KOR and not MOR.

KOR sensitivity and binding sites are increased in vSTR of RGS12null mice

Given the effect of KOR antagonism in reversing the DATmediated DA dysfunction of RGS12-null mice, we probed for changes in KOR signaling and/or levels upon RGS12 loss. Systemic administration of KOR agonists, including U50,488, reduces mouse locomotion [59] -an index of KOR sensitivity in vivo. Following $2.5 \mathrm{mg} / \mathrm{kg}$ U50,488, RGS12-null, but not wildtype, mice displayed hypolocomotion relative to vehicle-treated controls (Fig. 2c; RGS12-null: $p=0.012$; wildtype: $p=0.892$ ), indicating increased KOR sensitivity in RGS12-null mice. A higher dose $(5 \mathrm{mg} / \mathrm{kg})$ significantly reduced locomotion in both genotypes (Fig. 2c; RGS12-null: $p=0.000$; wildtype: $p=0.0007$ ). All data are the mean \pm SEM and analyzed by two-way ANOVA ( $n=7-13$ mice/group). Omnibus analyses of summed data (Fig. 2c) revealed an effect of genotype, U50,488 treatment, and a trend for a genotype $\times$ treatment interaction (genotype, $F(1,55)=4.4, p=0.040$; treatment, $F(2,55)=20.1, p<0.0001$; interaction, $F(2,55)=2.8, p=$ 0.072 ). Multiple comparisons were analyzed by a Sidak's post hoc test and performed with each dose of U50,488 statistically compared to saline-treated controls.

We also measured $\left[{ }^{35} \mathrm{~S}\right] \mathrm{GTP}$ S incorporation upon U50,488elicited G protein activation in vSTR and dSTR membranes. At 1 $\mu \mathrm{M}$ U50,488, RGS12-null, but not wildtype, mice displayed significant GTPYS incorporation in VSTR membranes (Fig. 2d) relative to vehicle control (RGS12-null [1 $\mu \mathrm{M}]: p=0.015$; wildtype $[1 \mu \mathrm{M}]: \quad p=0.996)$, supporting the notion of enhanced KORstimulated $G$ protein activation in the vSTR upon RGS12 loss. A two-way ANOVA of the data across multiple U50,488 dosings (Fig. 2d) revealed omnibus effects of genotype, U50,488 treatment, and a genotype $\times$ treatment interaction (genotype: $p=$ 0.005; treatment: 0.004, interaction: $p=0.015$ ).

vSTR and dSTR preparations from wildtype mice, as well as dSTR preparations from RGS12-null mice, only displayed significant $\left[{ }^{35} \mathrm{~S}\right]$ GTPYS incorporation at the highest concentration tested (Fig. $2 \mathrm{~d}$ : e.g., vSTR of wildtype mice at $100 \mu \mathrm{M}$ U50,488: $p=0.028$ ). Low signal window (e.g., $\sim 0.2$-fold $\max$ ) in assays of $\left[{ }^{35} \mathrm{~S}\right] \mathrm{GTP}$ S binding to endogenous receptors in native brain tissue has been previously noted [60]. U50,488-induced ${ }^{35}$ S]GTPYS binding was not differentially elevated in dSTR preparations from RGS12-null vs wildtype mice (Fig. $2 \mathrm{~d}$ inset: Student's $t$-test $t(7)=0.06 ; p=0.946$ ). All data from $\left[{ }^{35} \mathrm{~S}\right] \mathrm{GTP} \gamma \mathrm{S}$ incorporation are the mean \pm SEM $(n=$ 13-19 mice/group).

We next assessed whether increased KOR levels/binding sites, in addition to augmented KOR signaling, could account for KOR antagonism-mediated reversal of increased DA uptake in RGS12null mice. We performed saturation binding with the KORselective agonist $\left.{ }^{3} \mathrm{H}\right] \mathrm{U} 69,593$ on vSTR and dSTR membranes from RGS12-null mice vs wildtype controls. With loss of RGS12, KOR binding sites $\left(B_{\max }\right)$ were increased in vSTR (Fig. 2e) $(F(1,87)=12.9$, $p=0.0005)$, but not dSTR $\left(F(1,62)=0.3, p=0.618\right.$;); in contrast, $\mathrm{K}_{\mathrm{d}}$ values were equivalent between RGS12-null and wildtype mice in both vSTR $(F(1,87)=0.008, p=0.931)$ and dSTR $(F(1,62)=0.3$, 

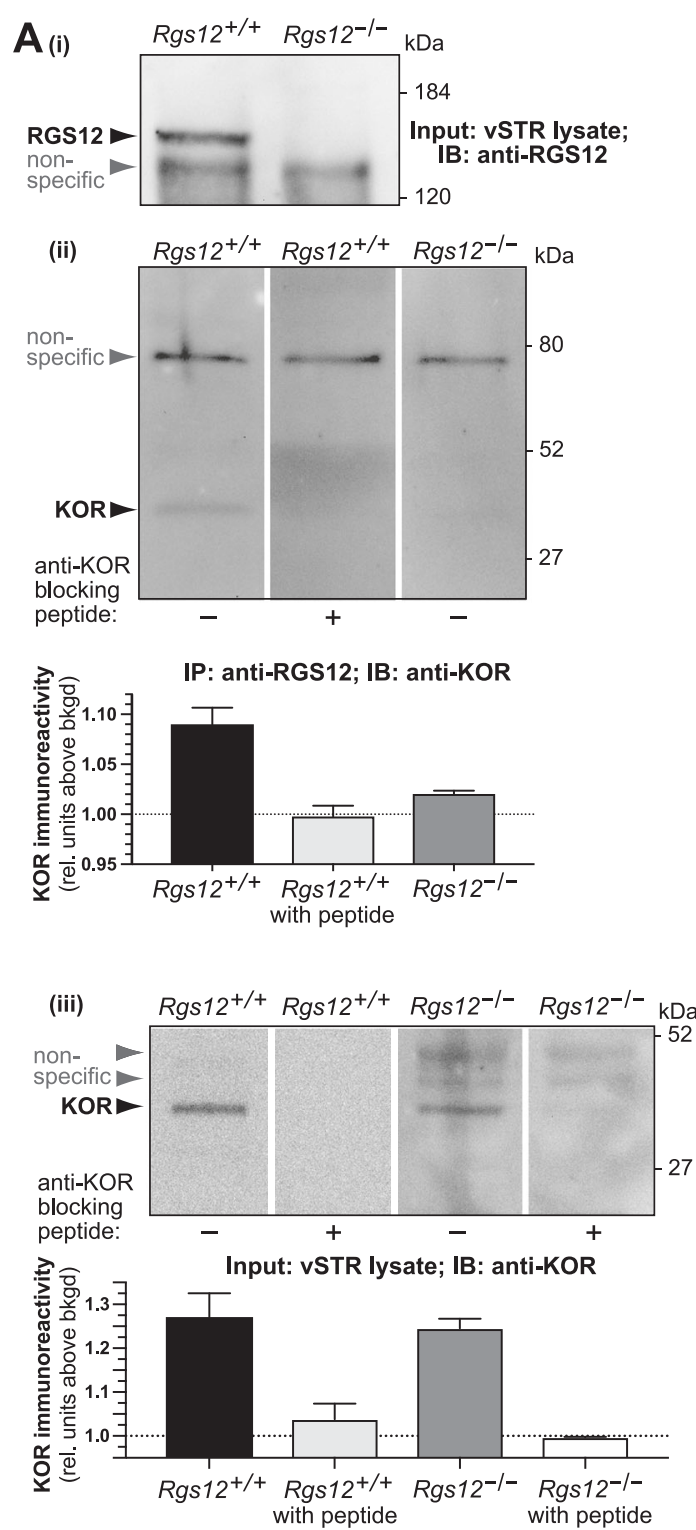

B

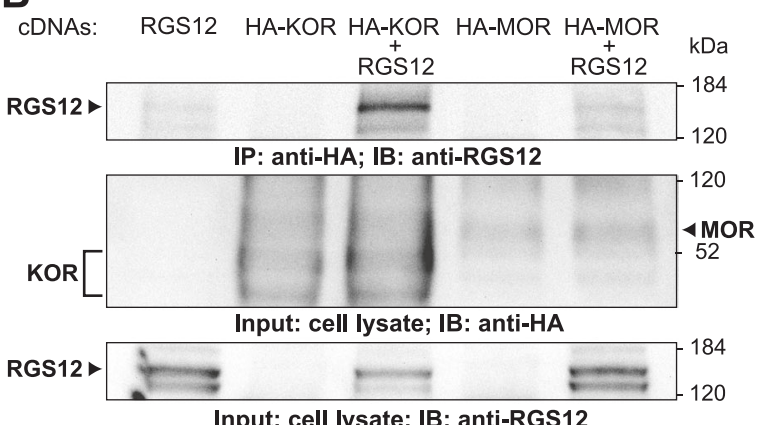

Input: cell lysate; IB: anti-RGS12

C $\mathrm{5000}_{7} \square$ vehicle
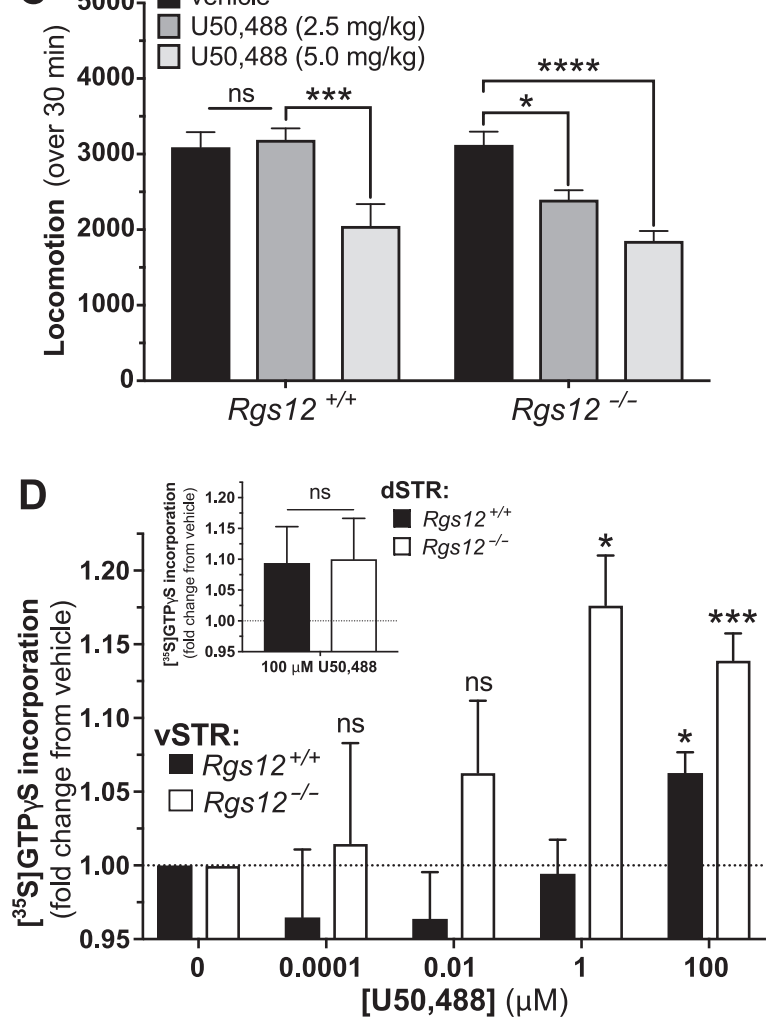

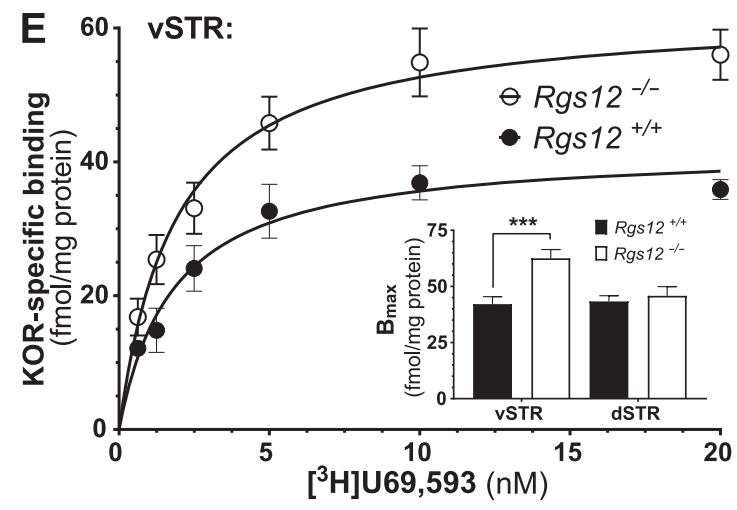

$p=0.610$ ) preparations. All data from $\left[{ }^{3} \mathrm{H}\right] \mathrm{U} 69,593$ saturation binding are the mean \pm SEM, and the inset of Fig. 2e was analyzed by two-way ANOVA ( $n=9-12$ mice/group), revealing an effect of genotype, brain region, and a genotype $\times$ brain region interaction (genotype, $F(1,24)=10.0, p=0.004$; region, $F(1,24)=4.6, p=$ 0.043 ; interaction, $F(1,24)=6.1, p=0.021)$; multiple comparisons were analyzed by Sidak's post hoc test (multiple comparisons: vSTR, RGS12-null vs wildtype, $p<0.0001$; dSTR, RGS12-null vs wildtype, $p=0.879$ ). To ascertain whether increased KOR protein levels/ binding sites in RGS12-null mice was due to KOR (Oprk1) transcriptional upregulation, we performed qRT-PCR on vSTR and midbrain tissue. RGS12-null and wildtype mice exhibited 
Fig. 2 RGS12 interacts with KOR and RGS12 loss results in elevated KOR sensitivity and binding sites in the vSTR. a Representative immunoblots indicating that KOR and RGS12 co-immunoprecipitate in the vSTR of wildtype mice ( $N=2$ experiments). Subpanel (i) indicates loss of RGS12 immunoreactivity within whole lysates of ventral striatum from Rgs12-null mice. Subpanel (ii) demonstrates that endogenous KOR protein is co-immunoprecipitated from ventral striatal lysate upon immunoprecipitation of endogenous RGS12 protein. Subpanels (ii) and (iii) indicate that immunoblots probed with a mixture of anti-KOR and an anti-KOR blocking peptide yield no KOR immunoreactivity, confirming antibody specificity. Immunoprecipitation of RGS12 in RGS12-null vSTR results in greatly reduced signal of KOR immunoreactivity (see densitometric quantitation below immunoblot of subpanel (ii)), supporting that KOR immunoreactivity in wildtype IP samples is not due to non-specific pull down. b Co-immunoprecipitation analyses of HEK293T cells transiently transfected with human opioid receptor (with Nterminal HA-tag) and/or full-length RGS12 vector DNA. Robust content of RGS12 is seen in the anti-HA antibody immunoprecipitate when RGS12 is co-expressed with KOR, whereas co-expression of the related opioid receptor MOR yields only non-specific binding signal (i.e., compare first vs last lanes). Parallel immunoblots containing whole cell lysates resolved by SDS-PAGE demonstrate the presence or absence of RGS12, KOR, and/or MOR expression in appropriate conditions. c Total locomotion (over 30 min) by RGS12-null mice and wildtype littermate controls following administration of U50,488. RGS12-null, but not wildtype, mice exhibit a hypolocomotor effect to $2.5 \mathrm{mg} / \mathrm{kg}$ U50,488 relative to vehicle controls. At $5 \mathrm{mg} / \mathrm{kg}$ U50,488, RGS12-null and wildtype controls both display reduced locomotor activity relative to vehicle controls. Data are the mean \pm SEM and tested by two-way ANOVA with Dunnet's post hoc test $\left(n=7-13\right.$ mice per group) (ns, $p>0.05 ;{ }^{*} p<0.05 ;{ }^{* * *} p<$ $0.001 ; * * * *<0.0001)$. d $\left[{ }^{35} \mathrm{~S}\right] \mathrm{GTP} \gamma \mathrm{S}$ incorporation into vSTR membranes from RGS12-null mice and wildtype littermate controls upon activation with KOR agonist U50,488. Data are normalized to vehicle (saline) control (expressed as fold change). vSTR membranes from RGS12null mice exhibit increased sensitivity to U50,488 relative to wildtype controls. Inset, $\left[{ }^{35} \mathrm{~S}\right] \mathrm{GTP} \gamma \mathrm{S}$ binding (at $100 \mu \mathrm{M}$ U50,488) by dSTR membranes from RGS12-null mice and wildtype littermate controls. All data are the mean \pm SEM and tested by two-way ANOVA with Sidak's post hoc test $\left(n=13-19\right.$ mice per group) $\left({ }^{*} p<0.05 ;{ }^{* *} p<0.001\right)$. e $\left[{ }^{3} \mathrm{H}\right] \mathrm{U} 69,593$ saturation binding analysis of vSTR membranes from RGS12null $\left(\right.$ Rgs $\left.12^{-/}\right)$mice and wildtype $\left(\operatorname{Rgs} 12^{++}\right)$littermate controls. Non-specific binding was determined in the presence of $10 \mu \mathrm{M}$ nor-BNI (KOR antagonist). Inset, As derived from data in panel $B$ and parallel binding data from dSTR membrane samples, $B_{\max }$ was quantified and seen to be increased in vSTR (but not dSTR) of RGS12-null mice (RGS12-null vSTR $B_{\max }=62.5 \pm 3.9 \mathrm{fmol} / \mathrm{mg}$ protein vs wildtype vSTR $B_{\max }=42.1 \pm 3.3$ $\mathrm{fmol} / \mathrm{mg}$ protein). The $\mathrm{K}_{\mathrm{D}}$ for $\left.{ }^{3} \mathrm{H}\right] \mathrm{U} 69,593$ did not differ across genotypes (RGS12-null vSTR: $1.8 \pm 0.4 \mathrm{nM}$; WT vSTR: $1.8 \pm 0.4 \mathrm{nM}$ ). Data are the mean \pm SEM and tested by two-way ANOVA with Sidak's post hoc test $\left(n=9-12\right.$ mice per group) $\left.{ }^{* * *} p<0.001\right)$

similar Oprk1 mRNA levels in both regions (Fig. S3A), suggesting that enhanced KOR activation observed in RGS12-null mice is not likely due to elevated KOR expression.

RGS12 differentially regulates $G$ protein and $\beta$-arrestin signaling downstream of KOR

KOR belongs to the GPCR family that includes mu- (MOR) and delta (DOR) opioid receptors - also $\mathrm{G}_{\mathrm{i} / \mathrm{o}}$-coupled, but with separate neuroanatomical distributions and functions relative to KOR $[61,62]$. To determine whether RGS12 regulates $G$ protein signaling downstream of opioid receptor activation, we used a cAMP-based readout in HEK293T cells [54] to measure receptormediated, $\mathrm{Ga}_{\mathrm{i} / \mathrm{o}}$-dependent inhibition of isoproterenol-induced CAMP increases (Fig. 3a-f). PTX pretreatment abolished KOR agonist-stimulated CAMP inhibition (Fig. 3a inset: $t(3)=18.1, p<$ 0.001 ), validating the luciferase assay as a measure of $\mathrm{G}_{\mathrm{i} / \mathrm{o}^{-}}$ mediated signaling. Wildtype (WT) RGS12 expression reduced U50,488 potency by at least 20-fold (Fig. 3a: $F(1,245)=56.8, p<$ 0.0001 ; also Fig. S4A), but only affected agonism of MOR by $\sim 3-$ fold (Fig. 3b: $F(1,216)=13.1, p=0.0004$; also Fig. S4B) and DOR by 2.5 -fold (Fig. 3c: $F(1,136)=7.6, p=0.007$ ). The effect of RGS12 expression on KOR-mediated $G$ protein signaling relied on both the GAP and GDI activities of RGS12, as loss-of-function mutations to either element within RGS12 curtailed the observed decrease in $\mathrm{plC}_{50}$ from 20-fold (RGS12 WT) to less than 4-fold (Fig. 3a: $\mathrm{RGS}^{\mathrm{E} 740 \mathrm{~K}}: F(1,205)=7.1, p=0.008 ; \mathrm{RGS}^{\mathrm{R} 1206 \mathrm{~F}}: F(1,173)=5.7$, $p=0.018$ ). We previously established that the E740K chargereversal mutation to RGS12 eliminates RGS domain GAP activity [63], whereas the R1206F mutation eliminates GoLoco motif GDI activity $[63,64]$.

The PDZ domain of RGS12 exhibits a high degree of similarity [32] to the first PDZ domain of NHERF1 ("Na+/H+ exchanger regulatory factor-1"). NHERF1 is known [65] to employ its first PDZ domain to bind directly to a PDZ docking site at the KOR C-terminus (aa 376-380: -NKPV-cooh), but does not bind MOR nor DOR (which both lack this C-terminal sequence). As RGS12 coimmunoprecipitates with KOR, but not MOR, in transfected cells (Fig. 2b), we tested whether such binding specificity was determined by a potential PDZ domain / GPCR C-terminal tail interaction. We mutated the last four amino acids of the KOR C-terminus (i.e., NKPV) to four alanine residues and, conversely, mutated the last four amino acids of the MOR C-terminus to that found in the wildtype KOR sequence (i.e., NKPV) (Fig. 3d). Co-expression of hRGS12-WT with hKOR $^{\text {AAAA }}$ diminished the RGS12-mediated reduction in U50,488 potency from 20-fold down to 4-fold (Fig. 3a vs e: $F(1,272)=5.0, p=0.024$ ). Conversely, substitution of the last four amino acids of MOR to the C-terminal PDZ docking site of KOR (i.e., MOR ${ }^{N K P V}$ ) was seen to enhance the RGS12-mediated reduction of DAMGO potency from 3-fold to 6-fold (Fig. $3 \mathrm{~b}$ vs f: $F(1,271)=32.1, p<0.0001$ ), constituting a 2-fold gain-of-function from the effect of RGS12 on wildtype MOR. Together, these data suggest that the PDZ docking site of KOR is necessary, but not sufficient in its entirety, to account for the selectivity RGS12 exerts on opioid agonist potency for KOR over the other opioid receptors.

To determine whether RGS12 also regulates G proteinindependent signaling from opioid receptors, we examined $\beta$-arrestin recruitment following receptor activation $[53,54]$. Expression of wildtype RGS12 augmented KOR agonistdependent $\beta$-arrestin recruitment by 3 -fold (Fig. 3g: $F(1,410)=$ $211, p<0.0001)$, but only mildly elevated MOR agonist-dependent $\beta$-arrestin recruitment (Fig. 3i: 1.2-fold; $F(1,314)=11.5, p=0.0008$ ) and DOR agonist-dependent $\beta$-arrestin recruitment (Fig. 3j: 1.1fold; $F(1,250)=17.6, p<0.0001)$; no potency changes $\left(E C_{50}\right)$ were observed for any opioid receptor agonist used: KOR/U50,488: $F(1,410)=0.3, p=0.598$; MOR/DAMGO: $F(1,314)=0.3, p=0.561$; and DOR/DADLE: $F(1,250)=1.6, p=0.205$ ) (Figs. $3 g, \mathrm{i}, \mathrm{j}$ ).

RGS domain and GoLoco motif loss-of-function mutants did not reverse the RGS12-dependent increase in $\beta$-arrestin recruitment downstream of KOR activation (Fig. $3 \mathrm{~g}$ ). RGS12 $2^{\mathrm{E} 740 \mathrm{~K}}$ elicited no change in the maximal efficacy $\left(E_{\max }\right)$ of KOR agonist-dependent $\beta$-arrestin recruitment relative to wildtype RGS12 (RGS12 ${ }^{\mathrm{E} 740 \mathrm{~K}}$ : $F(1,410)=2.1, p=0.148)$, whereas RGS12 ${ }^{\text {R1206F }}$ co-transfection resulted in a slight, but statistically significant, increase in KOR agonist-dependent $\beta$-arrestin recruitment relative to wildtype protein (RGS12 $\left.{ }^{\mathrm{R} 1206 \mathrm{~F}}: F(1,410)=20.9, p<0.0001\right)$. Together, these data indicate that RGS12 requires a functional RGS domain and GoLoco motif for its full effects on KOR-mediated $G$ protein signaling (Fig. 3a), but not for enhancing $\beta$-arrestin translocation to activated KOR (Fig. $3 g$ ), suggesting that RGS12 increases $\beta$ arrestin recruitment in a $G$ protein-independent manner. To confirm this idea, we evaluated KOR agonist-stimulated $\beta$-arrestin translocation following PTX pretreatment. Overnight PTX pretreatment had no effect on the RGS12-mediated increase in $\beta$-arrestin 

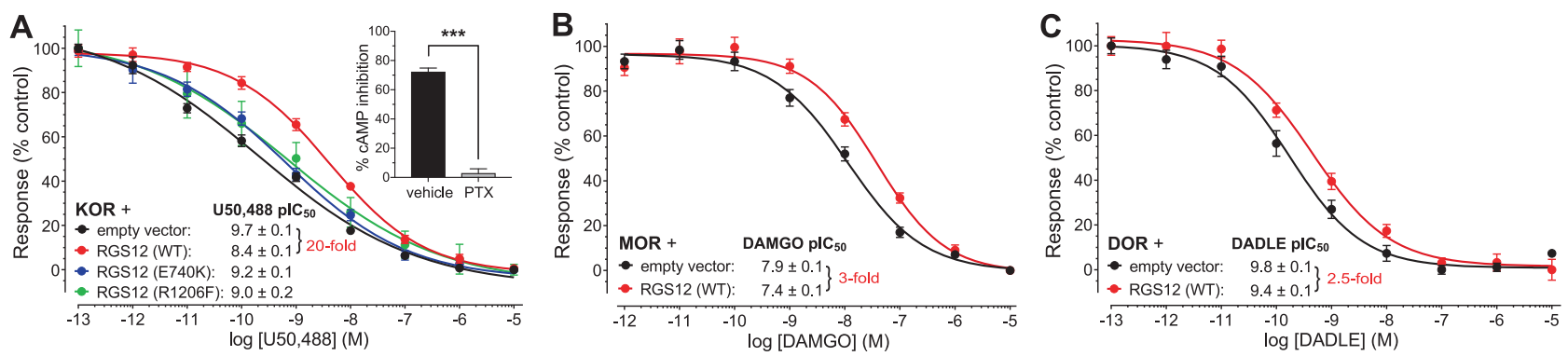
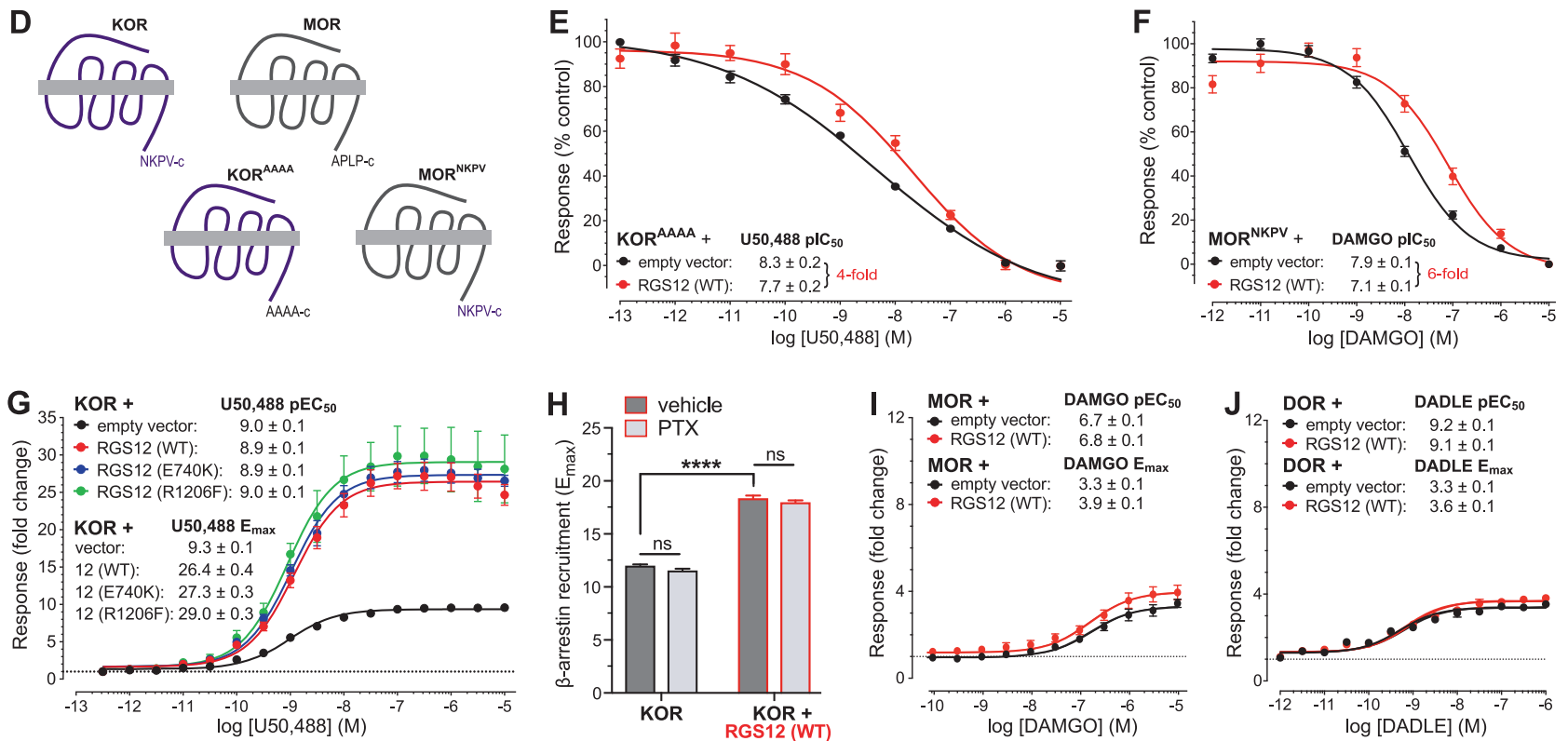

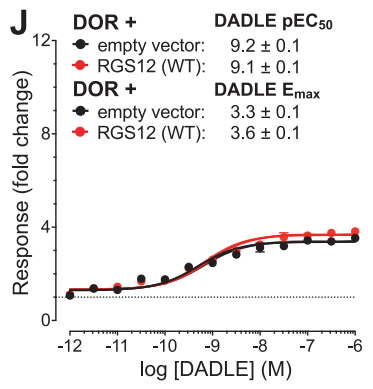

WT

Barr2 $^{\mathrm{KO}}$

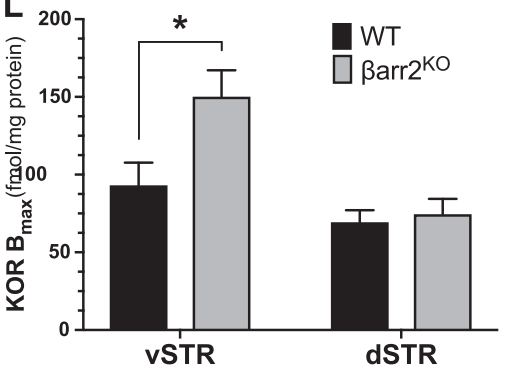

recruitment to activated KOR (Fig. 3h; $p=0.696$ ) nor an effect on U50,488-induced $\beta$-arrestin recruitment efficacy in control cells expressing KOR-only (Fig. 3h; $p=0.540$ ). Omnibus analyses revealed only an effect of RGS12 expression (RGS12, $F(1,8)=$ $1160.0, p<0.001)$. Data in Fig. $3 \mathrm{~h}$ are the mean \pm SEM $(N=3$ independent experiments) and were analyzed by two-way ANOVA with Sidak's post hoc test.

We hypothesized that the increased KOR binding sites seen in the vSTR of RGS12-null mice (Fig. 2e) might be due to attenuated $\beta$-arrestin-2-dependent internalization and/or downregulation of KOR in the absence of RGS12 expression. To test this idea, we performed $\left[{ }^{3} \mathrm{H}\right] \mathrm{U} 69,593$ saturation binding assays in vSTR and dSTR membranes of $\beta$-arrestin-2 knockout ( $\beta$ arr2 ${ }^{\mathrm{KO}}$ ) [55] and wildtype control mice. $\beta$-arrestin-2 knockout mice exhibited increased KOR $B_{\text {max }}$ in the vSTR compared to wildtype controls (Figs. 3k, l: $F(1,66)=4.1, p=0.044)$; in contrast, $\mathrm{K}_{\mathrm{d}}$ values for KOR radioligand binding were equivalent between $\beta$ arr ${ }^{\mathrm{KO}}$ and wildtype mice in both vSTR $(F(1,66)=0.1, p=0.701)$ and dSTR $(F(1,68)$ $=0.1, p=0.678$ ) preparations (Figs. $3 \mathrm{k}$, I). Analysis of KOR binding
$B_{\text {max }}$ revealed that KOR levels were increased in the vSTR, but not the dSTR (Fig. 3l: $F(1,68)=0.018, p=0.6674$ ). Omnibus analysis revealed effects of genotype, brain region, and a trend for a genotype $\times$ brain region interaction (genotype, $F(1,20)=5.8, p=$ 0.025 ; treatment, $F(1,20)=14.9, p=0.001$; interaction, $F(1,20)=$ $4.0, p=0.057)$. These findings support the notion that increased KOR levels/binding sites in RGS12-null mice is related to reduced KOR-mediated $\beta$-arrestin-2 function upon RGS12 loss. All data are the mean \pm SEM $(n=12$ mice per group); data displayed in Figs. 3k, I were analyzed by two-way ANOVA with Sidak's post hoc test.

RGS12 differentially regulates $G$ protein- and $\beta$-arrestin-dependent behaviors mediated by KOR

RGS12 expression selectively reduces KOR agonist-induced cAMP inhibition via its RGS domain and GoLoco motif (Fig. 3); these data are consistent with findings of KOR antagonism-mediated reversal of elevated DA uptake and DAT binding sites (Figs. 1a, b) and attenuated $\mathrm{AMPH}$-induced hyperlocomotion (Fig. 1c), increased 
Fig. 3 RGS12 expression reduces potency of the KOR agonist U50,488, yet augments agonist-stimulated recruitment of $\beta$-arrestin to KOR via independent mechanisms. a-c RGS12 expression reduces potency of the KOR agonist U50,488 to a greater extent than for the MOR agonist DAMGO or the DOR agonist DADLE. GloSensor-22F (Promega) luciferase-based measurements of cAMP levels within HEK293T cells stimulated with $100 \mathrm{nM}$ isoproterenol and simultaneously treated with opioid receptor-selective agonists following transient co-expression of (a) KOR cDNA plus indicated RGS12 expression plasmids, b MOR CDNA with or without wildtype (WT) RGS12, or c DOR CDNA with or without WT RGS12. (a, inset) PTX ( $200 \mathrm{ng} / \mathrm{mL})$ pretreatment abolished KOR agonist-driven cAMP inhibition, confirming that the assay is dependent on $\mathrm{G}_{\mathrm{i} / \mathrm{o}^{-}}$ mediated signaling. Wildtype RGS12 expression reduced U50,488 potency by 20-fold, i.e., 6 to 8 -fold more than its effects on DAMGO (3-fold) and DADLE (2.5-fold) potency. Loss-of-function point mutants of RGS12 curtailed U50,488 potency reductions from 20-fold down to 3-to-4fold. Data were normalized to vehicle control conditions and are expressed as the mean \pm SEM from multiple experiments $(N=3)$. Concentration-response curves were fit by four-parameter non-linear regression (Prism 7). d-f The PDZ domain docking site of KOR (-NKPV-c) is necessary, but not sufficient, to completely account for the specificity of RGS12 for KOR over MOR in assays of GPCR-mediated G protein signaling. $\mathbf{d}$ Schematic representing creation of KOR expression CDNA containing mutation to the C-terminus (-NKPV-c to -AAAA-c) and MOR expression cDNA containing mutation of its wildtype C-terminus (MOR: -APLP-c) to KOR's wildtype C-terminus (-NKPV-c). e Mutation to the Cterminus of KOR curtailed RGS12-mediated U50,488 potency reductions from 20-fold (e.g., panel a) to 4-fold. $f$ RGS12 reduced MOR agonist potency by 6-fold following substitution of the MOR C-terminus with the wildtype KOR C-terminus, relative to a 3-fold potency reduction observed with wildtype MOR (e.g., panel b). Data are normalized to vehicle control and expressed as mean \pm SEM from $N=3$ experiments. Dose-response curves fit by four parameter non-linear regression (Prism). g-j RGS12 expression augments agonist-stimulated recruitment of $\beta$ arrestin to KOR, but not MOR nor DOR, in a G protein-independent manner. Tango assays of $\beta$-arrestin recruitment within HTLA cells [53, 54] stimulated with indicated agonists following transient co-expression of (g) KOR CDNA plus indicated RGS12 expression plasmids, (h) KOR cDNA with or without WT RGS12 following pretreatment with PTX or vehicle, (i) MOR CDNA with or without WT RGS12, or (j) DOR cDNA with or without WT RGS12. Agonist potency ( $\mathrm{pEC} \mathrm{C}_{50}$ values) did not differ between conditions. U50,488-induced $\beta$-arrestin recruitment efficacy was 3-fold greater when either WT RGS12, or loss-of-function point mutants of RGS12, was co-expressed with KOR, whereas WT RGS12 only increased $\beta$-arrestin recruitment to MOR by 1.2 -fold and DOR by 1.1 -fold. PTX pretreatment did not affect U50,488-induced $\beta$-arrestin recruitment to KOR (panel $\mathrm{H}$ ) in the presence or absence of WT RGS12. Data were normalized to vehicle control conditions (fold change) and are expressed as the mean \pm SEM from multiple experiments $(N=3)$. Curves were analyzed by three-parameter non-linear regression and panel $\mathrm{H}$ was analyzed by two-way ANOVA with Sidak's post hoc test. $\mathbf{k}\left[{ }^{3} \mathrm{H}\right] \mathrm{U} 69,593$ saturation binding analysis of vSTR membranes from $\beta$ arrestin-2 knockout $\left(\beta a r r 2{ }^{\mathrm{KO}}\right.$ ) mice and wildtype (WT) controls. I As derived from data in panel $\mathrm{K}$ and parallel binding data from dSTR membrane samples, $B_{\max }$ was increased in vSTR (but not dSTR) of $\beta$-arrestin-2 knockout ( $\beta$ arr2 ${ }^{\mathrm{KO}}$ vSTR $\mathrm{B}_{\max }=150.1 \pm 17.1 \mathrm{fmol} / \mathrm{mg} \mathrm{protein}$ vs wildtype vSTR $B_{\max }=93.1 \pm 14.6 \mathrm{fmol} / \mathrm{mg}$ protein; $\beta$ arr $2^{\mathrm{KO}}$ dSTR $B_{\max }=74.5 \pm 9.8 \mathrm{fmol} / \mathrm{mg}$ protein vs wildtype dSTR $B_{\max }=69.3 \pm 7.7 \mathrm{fmol} / \mathrm{mg}$ protein). The $\mathrm{K}_{\mathrm{D}}$ for $\left[{ }^{3} \mathrm{H}\right] \mathrm{U} 69,593$ did not differ across genotypes ( $\beta$ arr2 ${ }^{\mathrm{KO}}$ vSTR: $7.1 \pm 1.8 \mathrm{nM}$; WT vSTR: $8.4 \pm 2.9 \mathrm{nM} ; \beta$ arr2 ${ }^{\mathrm{KO}}$ dSTR: $7.8 \pm 2.3 \mathrm{nM}$; WT dSTR: $6.6 \pm 1.7 \mathrm{nM}$;). Data are the mean \pm SEM and panel $L$ was analyzed by two-way ANOVA with Sidak's post hoc test $(n=12$ mice per group) $\left({ }^{*} p<0.05\right)$

KOR-stimulated $\left[{ }^{35} \mathrm{~S}\right] \mathrm{GTP}$ S binding (Fig. 2d), and increased sensitivity to KOR-stimulated hypolocomotion (Fig. 2c) upon RGS12 loss. Together, these findings suggest that RGS12 normally reduces $G$ protein-dependent KOR signaling, and RGS12 loss results in hypersensitivity of KOR-mediated $G$ protein signaling. To assess this hypothesis with an integrated, behavioral output, we interrogated supraspinal nociception using the hot plate assay [66]; prior studies have determined that KOR-induced analgesia represents a $G$ protein-dependent and $\beta$-arrestin-independent outcome of KOR agonism [7, 15, 30]. Here, we tested whether RGS12-null mice exhibit enhanced sensitivity to the analgesic effect of U50,488 (Fig. 4a-c). RGS12-null mice displayed significantly increased analgesia by U50,488 at $5 \mathrm{mg} / \mathrm{kg}$ (within-subjects comparisons: RGS12-null saline vs U50,488: $p=0.033$ ) and 22.5 $\mathrm{mg} / \mathrm{kg}$ (RGS12-null saline vs U50,488: $p=0.005$ ), whereas wildtype littermates exhibited no statistically significant analgesia to either dose (within-subjects comparisons: WT saline vs $5 \mathrm{mg} / \mathrm{kg}$ U50,488: $p=0.815$; WT saline vs $22.5 \mathrm{mg} / \mathrm{kg}$ U50,488: $p=0.199$ ). Omnibus ANOVA revealed only a significant effect of treatment at these two doses of U50,488 $(5 \mathrm{mg} / \mathrm{kg}$ treatment, $F(1,18)=5.2, p=0.036$; $22.5 \mathrm{mg} / \mathrm{kg}$ treatment, $F(1,15)=13.8, p=0.002)$. These results suggest that RGS12-null mice have enhanced sensitivity to the analgesic output of KOR agonism. Following $30 \mathrm{mg} / \mathrm{kg}$ U50,488, there was no difference in analgesia between genotypes (Fig. $4 \mathrm{c}$ : RGS12-null saline vs U50,488: $p<0.0001$; WT saline vs U50,488: $p$ $=0.0003$ ); omnibus ANOVA revealed only a significant effect of treatment at this $30 \mathrm{mg} / \mathrm{kg}$ dose of U50,488 (treatment, $F(1,16)=$ 57.6, $p<0.0001)$. RGS12-null and wildtype mice pretreated with the KOR antagonist nor-BNI ( $10 \mathrm{mg} / \mathrm{kg}$, ip) $24 \mathrm{~h}$ prior to U50,488 administration exhibited no analgesic responses (Fig. S5), indicating that the supraspinal anti-nociceptive effects of U50,488 (Figs. 4a-c) are mediated by KOR activation. Supporting a selective function of RGS12 on KOR signaling over that of other opioid receptors, RGS12-null mice were seen to exhibit normal analgesia to morphine (Fig. S6) - a response dependent on MOR activation $[66,67]$. All data from hot plate analgesia experiments are the mean \pm SEM ( $n=7-14$ mice per group) and analyzed by two-way ANOVA followed by Sidak's post hoc test.

While RGS12 is known to suppress G protein-dependent signaling $[32,64]$, RGS12 expression was also seen to augment $\beta$-arrestin recruitment independent of its heterotrimeric $G$ proteinmodulating domains (Fig. 3g). These data suggest that RGS12 loss may lead to decreased $G$ protein-independent (i.e., $\beta$-arrestin) signaling downstream of KOR activation. Therefore, we examined conditioned place aversion (CPA) to U50,488, given that aversion to KOR-induced dysphoria is considered a $\beta$-arrestin-dependent behavior [14, 28, 68]. Wildtype mice exhibited CPA following 2.5 $\mathrm{mg} / \mathrm{kg} \mathrm{U} 50,488$ ( $p=0.011$ ); in contrast, RGS12-null mice did not express aversion at this dose $(p=0.548)$. Omnibus ANOVA analysis revealed only an effect of U50,488 treatment $(F(1,25)=7.7, p=$ 0.010 ) (Fig. 4d). These data suggest that RGS12 loss reduces the ability of KOR agonism to produce aversion/dysphoria. At $5 \mathrm{mg} / \mathrm{kg}$ U50,488, both RGS12-null and wildtype mice exhibited aversion (Fig. 4e) (within-subjects comparison: RGS12-null mice: $p=0.021$; WT mice: $p<0.0001$ ); the aversion exhibited by RGS12-null mice was attenuated relative to that of wildtype littermates (betweensubjects comparison: RGS12-null vs WT: $p=0.006$ ). Omnibus ANOVA analysis revealed an effect of treatment at this higher U50,488 dose (treatment, $F(1,22)=44.7, p<0.0001$ ) and a genotype $\times$ treatment interaction $(F(1,22)=10.7, p=0.004)$. All data from CPA experiments are the mean \pm SEM $(n=9-15$ mice per group) and analyzed by two-way ANOVA followed by a Sidak's post hoc test.

A summary of the interpretation of all these findings, derived from our interrogations of adult RGS12-null mice, is presented in Fig. 5. Constitutive loss of RGS12 may alternatively (or additionally) engender disruptions to KOR signaling in the VSTR via perturbation of neurodevelopmental processes. In response to neonatal or early life stress, the KOR/dynorphin system becomes hypersensitive to endogenous and exogenous activation, resulting in mesolimbic hypodopaminergia and behavioral disruption in adulthood, including altered psychostimulant responsiveness 


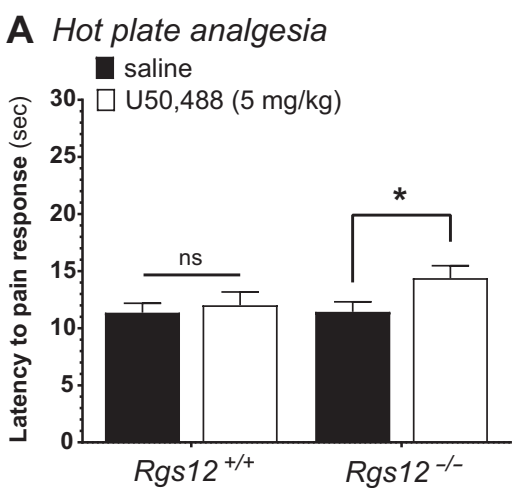

D Conditioned place aversion

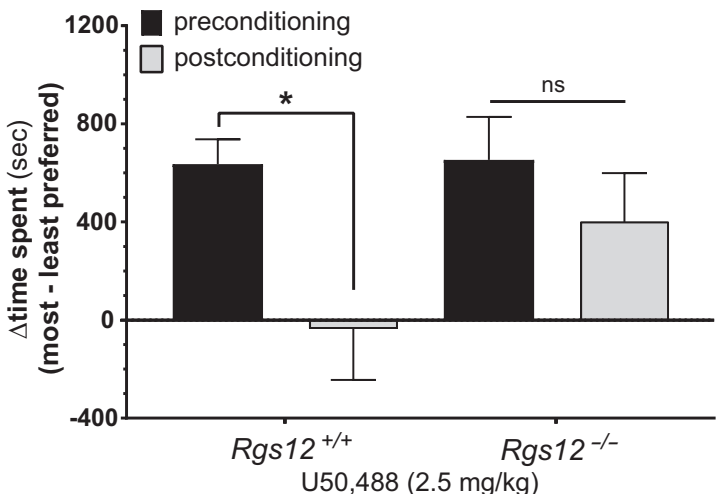

B

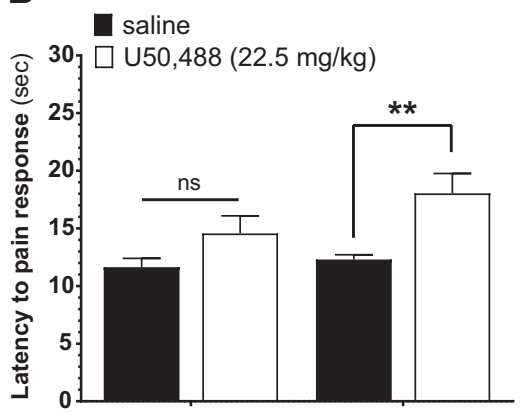

$\operatorname{Rgs} 12^{+/+}$

Rgs12-/-
C

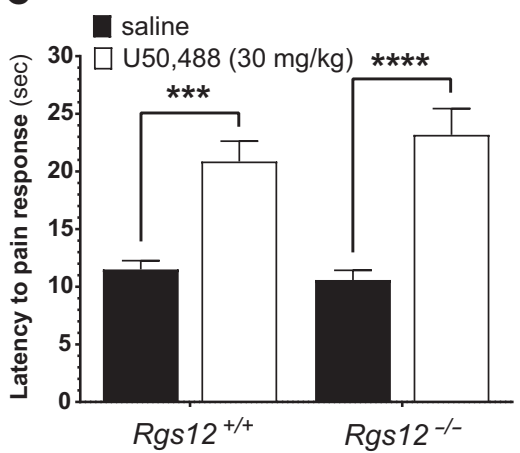

E

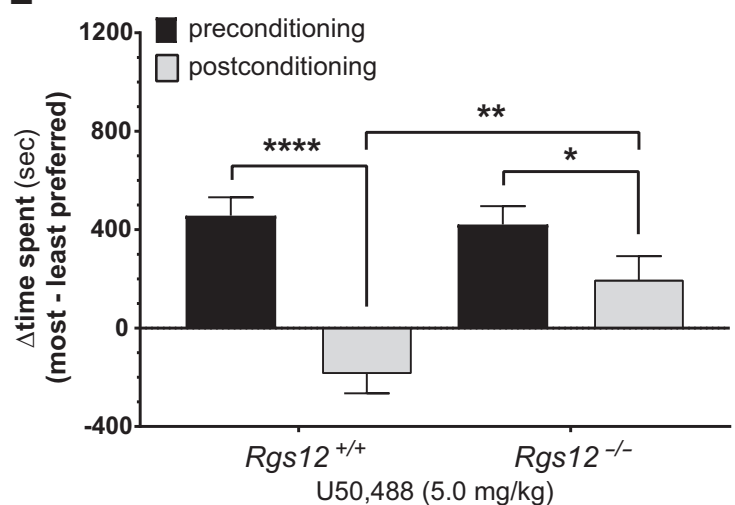

Fig. 4 RGS12-null mice exhibit a heightened sensitivity to the analgesic effect of U50,488 administration but attenuated conditioned place aversion (CPA) to the aversive effects of U50,488. U50,488-induced analgesia at a dose of (a) $5 \mathrm{mg} / \mathrm{kg}$, (b) $22.5 \mathrm{mg} / \mathrm{kg}$, or (c) $30 \mathrm{mg} / \mathrm{kg}$ was measured in RGS12-null (Rgs $\left.12^{-1-}\right)$ mice vs WT $\left(\operatorname{Rgs} 12^{+/+}\right)$littermate controls using a hot plate latency test. Data are the mean \pm SEM and tested by two-way repeated-measures (within-subjects design) ANOVA followed by Sidak's post hoc test ( $n=8-10$ mice per group) ( $n$ s not significantly different; ${ }^{*} p<0.05 ;{ }^{* *} p<0.01 ;{ }^{* * *} p<0.001 ;{ }^{* * *} p<0.0001$ ). d-e RGS12-null mice exhibit attenuated conditioned place aversion (CPA) to the aversive effects of U50,488. $2.5 \mathrm{mg} / \mathrm{kg}$ (d) or $5.0 \mathrm{mg} / \mathrm{kg}$ (e) of U50,488 was administered to RGS12-null (Rgs12 ${ }^{-1-}$ ) mice and WT $\left(\right.$ Rgs $12^{+/+}$) littermate controls to test for conditioned place aversion (a measure of the dysphoric property of KOR agonism). Data are the mean \pm SEM and tested by two-way repeated-measures ANOVA (for within-subjects comparisons) and between-subjects ANOVA (for betweensubjects comparisons) each followed by Sidak's post hoc test $\left(n=8-15\right.$ mice per group; $\left.{ }^{*} p<0.05 ;{ }^{* *} p<0.01 ;{ }^{* * * *} p<0.0001\right)$

[4, 69-71]. Thus, loss of RGS12 from birth may increase pre- and/or post-natal stress susceptibility such that the KOR system becomes upregulated. This hypothesis is supported by previous work from our group and others demonstrating that (i) RGS12 is strongly expressed throughout CNS regions integral to the early embryonic stages of neurodevelopment [72], (ii) RGS12 is required for neurodevelopmental processes such as nerve growth factorstimulated axonogenesis by sensory neurons [38], and (iii) RGS12 levels are altered during synaptogenesis by sensory deprivation [73] and in transgenic models of neurodevelopmental diseases such as schizophrenia [74]. Future studies will be required to elucidate whether RGS12 loss early in neurodevelopment contributes to the disruptions of KOR signaling and behavior observed in constitutive RGS12-null adult mice.

\section{DISCUSSION}

RGS12 as an important regulator of vSTR DA homeostasis via KOR signaling effects on DAT

RGS12 exhibits selective effects on KOR signaling in at least one region of the CNS - the ventral striatum-via a mechanism dependent on an interaction with KOR that is at least functional and likely direct. Single-cell RNAseq data [75] reveals that Rgs 12 is expressed in several Oprk1 (KOR)-expressing neuronal populations within the corticostriatal circuit (Fig. S1C). Thus, disruptions to KOR signaling and behavior upon global Rgs12 deletion may, at least in part, reflect an integrated response across several corticostriatal brain-regions and may not necessarily be restricted to abrogated functional interaction solely within the vSTR. For example, loss of Rgs 12 in striatal-dopamine receptor $\mathrm{D} 1 \mathrm{R}+$ and/or $\mathrm{D} 2 \mathrm{R}+$ medium-spiny-neurons (MSNs) seen to co-express Oprk1 and Rgs12 in wildtype-mice (e.g., Fig. S1C) could contribute to the RGS12-null mouse phenotypes observed, especially given the known roles these MSNs play in rewarding and aversive responses (e.g., to psychostimulantdrugs) $[76,77]$.

KOR activation results in hypodopaminergia in the vSTR/NAc by (i) decreasing DA release $[46,47]$ and (ii) increasing DAT-mediated DA-reuptake $[48,49]$ in a G-protein-dependent manner. As RGS12null mice exhibit augmented DAT-mediated DA-uptake reversible by KOR-blockade, and display increased KOR-mediated $\mathrm{G}$ protein signaling (Figs. 1, 2), we hypothesized that RGS12 loss would also reduce DA-release in the VSTR/NAc due to increased KORmediated G protein signaling. Indeed, RGS12-null mice exhibited attenuated DA-release in the NAc-core (Fig. 1); in addition, a notable trend towards reduced DA-release was also observed in the NAc-shell, but this latter result was not statistically different from wildtype-controls. Evoked DA-release is considerably lower in the NAc-shell than the core [78], which may account for our inability to attain statistically significant differences between genotypes when performing FSCV in the shell. No differences of DA-release nor in nor-BNI pretreatment effects were detected in the dSTR (Fig. S2), further supporting that RGS12 selectively exerts DA-modulatory effects in the vSTR, but not dSTR. 

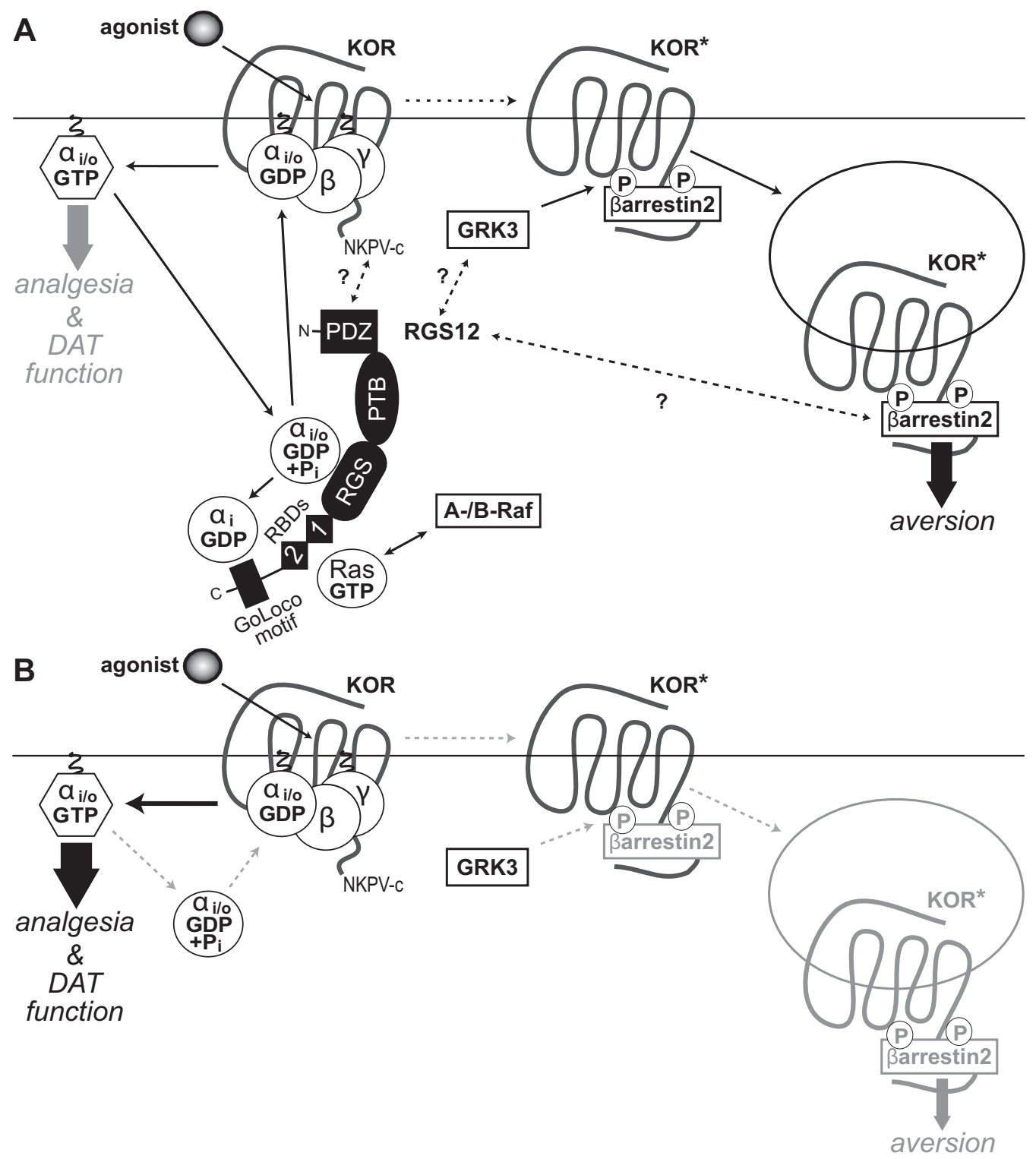

Fig. 5 Proposed model of RGS12 action in the differential outputs of KOR-activated signaling. a Agonist-induced activation of KOR dissociates $\mathrm{G}_{\mathrm{i} / \mathrm{o}}$-coupled heterotrimers into free $\mathrm{G}$ protein subunits, evokes $\mathrm{G}$ protein-dependent signal transduction (thick grey arrow) and, ultimately, produces analgesia and regulates DAT function. RGS12 expression is seen to reduce KOR-mediated G protein signaling via its central RGS domain (by accelerating GTP hydrolysis of $\mathrm{G} \alpha_{\mathrm{i} / \mathrm{o}} \cdot \mathrm{GTP}$ ) and its C-terminal GoLoco motif (by binding $\mathrm{G}_{\mathrm{i}} \cdot \mathrm{GDP}$ ). RGS12 also contains an N-terminal PDZ domain that interacts with MEK2 [38] and findings from this study suggest interaction with the C-terminal PDZ domain docking site of KOR (NKPV-C). RGS12 also contains tandem Ras-binding domains (RBDs) that interact with activated H-Ras and A-/B-Raf to enable MAPK/ERK scaffolding properties [38]. Agonist-stimulated KOR activation is also known to drive GRK3-dependent $\beta$-arrestin-2 recruitment [103], resulting in receptor internalization, $\beta$-arrestin-dependent signal transduction (thick black arrow) and, ultimately, aversive behavior. RGS12 expression is seen to augment KOR agonist-stimulated $\beta$-arrestin recruitment independent of its GAP and GDI activity, suggesting that RGS12 may modulate GRK3 activity on activated KOR (KOR*) and/or enhance $\beta$-arrestin- 2 recruitment and/or function by as yet undetermined molecular mechanisms (represented by question marks over dashed arrows). b Loss of RGS12 in mice results in concomitant increases in KOR-mediated G protein signaling and decreases in $\beta$-arrestin-2 recruitment, thus resulting in enhanced KOR agonist-stimulated analgesia and disrupted DAT function (thicker black arrow), as well as an attenuation of KOR-stimulated aversion (thinner grey arrow), respectively

KOR-blockade via nor-BNI pretreatment did not rescue the deficient DA-release seen in the NAc-core of RGS12-null-mice (Fig. 1), suggesting that this release defect is KOR-independent or reliant on long-term neurodevelopmental maladaptation to RGS12 loss rather than acute KOR-signaling upregulation per se. We identified a trend for nor-BNI pretreatment to increase DArelease in RGS12-null, but not wildtype, mice within the NAc shell at select stimulation amplitudes (Fig. 1), although this did not reach statistical significance. KOR-agonists have been reported to reduce DA-release more potently in the NAc-shell than the core
[78], and this effect may relate to the higher level of KOR expression in the NAc-shell relative to the core seen in rodents $[79,80]$. Therefore, the observed trend for increased DA-release by nor-BNI in the NAc-shell, but not NAc-core, of RGS12-null mice may have emerged given enhanced expression and function of KOR in the NAc-shell over the core.

Wildtype-mice did not exhibit altered DA-reuptake in the NAc-core, NAc-shell, nor dSTR following nor-BNI pretreatment (Figs. 1, S2); these observations support the notion that, under normal conditions, there is a lack of basal KOR-tone (i.e., the 
1738

presence of dynorphin-stimulated and/or constitutive activity of $\mathrm{KOR}$ ) in these regions. However, augmented $\left[{ }^{3} \mathrm{H}\right] \mathrm{DA}$-uptake in the vSTR-synaptosomes of RGS12-null-mice was reversed by systemic nor-BNI pretreatment (Fig. 1); moreover, RGS12-null mice display a trend for enhanced sensitivity to the effect of nor-BNI on DA-reuptake in the NAc-core relative to wildtype-controls (Fig. 1). Together, these data support the idea that KOR sensitivity/activity in the vSTR is enhanced in the absence of RGS12 expression. This effect is unlikely to be related to elevated dynorphin-tone, given normal Prodyn-mRNA expression in RGS12-null mice (Fig. S3B). RGS12-null mice may not exhibit KOR-dependent effects on DAreuptake in the NAc-shell given that this region expresses considerably less DAT than the NAc-core [81]. Moreover, the minimal levels of extracellular DA that arise following evoked DArelease in the NAc-shell, especially in RGS12-null mice, may be insufficient to drive DAT-mediated DA-reuptake at thresholds sufficient to engage KOR, thereby masking any modulatory effects that RGS12 may have on KOR-dependent processes. Irrespective of the relative paucity of engagement within the NAc-shell leading to a lack of observable signal, our data from brain-slice FSCV and synaptosomal $\left[{ }^{3} \mathrm{H}\right] \mathrm{DA}$ uptake support that (i) RGS12 loss affects DAergic neurotransmission in vSTR, but not the dSTR, and (ii) RGS12 modulates vSTR-KOR signaling that affects DAT function, but does not appreciably affect KOR signaling that specifically regulates DA-release.

vSTR-synaptosomes derived from RGS12-null mice exhibit elevated- $\mathrm{V}_{\max }$ of $\left[{ }^{3} \mathrm{H}\right] \mathrm{DA}$ uptake [40]. In contrast, DA-reuptake in the NAc is similar in saline-treated RGS12-null mice and salinetreated wildtype controls (Fig. 1). Such differences between measurements of endogenous DA-reuptake (e.g., via FSCV) vs exogenous DA-uptake (e.g., via synaptosomal $\left[{ }^{3} \mathrm{H}\right] \mathrm{DA}$-uptake) have been demonstrated previously [82]. FSCV evaluates DA-reuptake by quantifying the clearance-rate $\left(t_{1 / 2}\right)$ of endogenous DA released into the extracellular-space following stimulation of release (e.g., electrical) [56, 83]. Thus, FSCV-derived reuptake rates are predicated, in part, on the absolute quantity of DA released from presynaptic DA-neurons. Given that RGS12-null mice exhibit markedly reduced DA-release in the NAC following electricalstimulation (Fig. 1), these mice may consequently display lower rates of DA-reuptake than expected (relative to observed synaptosomal $\left[{ }^{3} \mathrm{H}\right] \mathrm{DA}$-uptake rates) simply due to the considerably lower levels of extracellular DA present during the experiment. Unlike in brain-slice FSCV [84, 85], in vitro synaptosomal $\left[{ }^{3} \mathrm{H}\right] \mathrm{DA}$ uptake experiments employ high-levels of both $\left[{ }^{3} \mathrm{H}\right]$-labeled and unlabeled-DA to achieve DAT saturation (e.g., refs. [40, 86]). Consequently, this high-load of exogenous DA produces a distinctly different measure of DA-uptake capacity relative to FSCV $[87,88]$ given that it drives activation of endogenously expressed-receptors and thereby engages negative-feedback systems (e.g., ref. [88]). Thus, RGS12-null mice may require elevated DA-tone in the vSTR/NAc to manifest observable differences in DAT-mediated DA-uptake.

Our finding that RGS12 modulates KOR function (this study) and DAT function [40] in the vSTR, but not dSTR, supports previous findings that KOR effects on DAT function and AMPH-induced neuronal-activation are restricted to the VSTR [48, 89]. Regiospecific RGS12 action on KOR and DAT function might be, at least in part, related to the greater RGS12-expression seen in vSTR relative to dSTR [40]. An alternative (or additive) explanation might be differential expression of some G-protein-signaling element(s) between the vSTR and dSTR. For example, DA-signaling via the dopamine- $\mathrm{D}_{2}$-receptor is reported as being more potent in the NAc (vSTR) than the dSTR [90], given preferential coupling of $D_{2} R$ to $\mathrm{Ga}_{\mathrm{o}}$, which is more highly-expressed in the NAc than dSTR relative to $\mathrm{Ga}_{i}$ [91]. While the RGS12 RGS-domain increases the GTPase-activity of both $\mathrm{Ga}_{\mathrm{o}}$ and $\mathrm{Ga}_{\mathrm{i} 1}$ proteins [32], the GoLocomotif binds only to $\mathrm{Ga}_{\mathrm{i} 1 / \mathrm{i} 2 / \mathrm{i3}}$ subunits and not to $\mathrm{Ga}_{\mathrm{o}}$ [64]. Such differential engagement of $\mathrm{Ga}_{\mathrm{i}} v s \mathrm{Ga}_{\mathrm{o}}$ by RGS12 might thereby underlie a vSTR-specific action of RGS12 on KOR-signaling and, consequently, on DAT-function.

RGS12 as a potential target for inhibition to help direct KOR agonism toward beneficial analgesia and away from anti-

therapeutic aversion/dysphoria?

Neuroanatomical loci mediating supraspinal opioid-induced analgesia are located throughout the brain [92, 93], with the mesolimbic dopamine-system playing an integral role [94, 95]. Thus, the enhanced analgesic-effect of U50,488 in RGS12-nullmice (Fig. 4) is consistent with the augmented KOR-agonist potency and KOR-levels observed in the vSTR of these mice (Fig. 2). RGS12 may also regulate KOR-mediated spinal-analgesia via similar mechanisms: RGS12 and KOR are both expressed in spinal-neurons that mediate analgesia [38, 96, 97]. Dorsal-rootganglion (DRG) neurons located adjacent to the spinal-cord, as well as the dorsal-horns, represent key nociceptive loci as they contain neurons responsible for receiving and transmitting nociceptive-signals [98]. Both KOR and RGS12 are highly expressed in DRGs [38, 99], and KOR is known to mediate analgesic responses within this anatomical-region [100]. Thus, the effects of RGS12-loss on KOR-mediated analgesia may also rely, at least in part, on augmented KOR-mediated G protein-signaling at the level of the spinal-cord. RGS12-null-mice exhibited normal morphine-induced analgesia (Fig. S6), supporting the idea that RGS12 functions selectively on KOR-signaling relative to that of other opioid-receptors, especially given the receptor-selectivity of morphine's analgesic actions (i.e., the anti-nociceptive effects of morphine are completely lost in MOR-knockout-mice $[66,67]$ yet preserved in mice lacking KOR [101]).

Prior evidence suggests that the DA-lowering effects of KORagonists in the vSTR underlie their aversive/dysphoric properties [44, 102]; thus, attenuated U50,488-induced CPA in RGS12-nullmice might be related to a constitutively elevated DA-reuptake in the vSTR of these mice [40], resulting in reduced extracellular-DA and causing a "floor effect" whereby KOR-mediated reductions in VSTR-DA are unable to manifest aversion in the absence of RGS12expression. However, this possibility is unlikely, as even DAdeficient mice display KOR-induced-CPA [68]. Reduced KORinduced-CPA in RGS12-null mice is also unlikely to reflect a learning deficit given that these mice exhibit normal conditionedplace-preference to both amphetamine and cocaine [40].

RGS12 over-expression was seen to reduce $G$ protein-dependent signaling and increase $\beta$-arrestin recruitment downstream of KOR-activation (Fig. 3). Consistent with these findings, Rgs 12 ablation enhances KOR-stimulated $\mathrm{G}$ protein activation and sensitivity to U50,488-induced hypolocomotion (Fig. 2). KORinduced hypolocomotion is unaffected by $\beta$-arrestin-2-knockout [15], suggesting that reduced-locomotion upon KOR activation is G-protein-dependent. RGS12-null-mice also exhibit increased KORbinding sites (a measure of protein expression) (Fig. 2) despite normal Oprk1-mRNA levels (Fig. S3), suggesting that elevated KOR levels/binding sites are not due to Oprk1 transcriptional upregulation. Increased KOR-protein levels and/or sensitivity, and not dynorphin expression levels (Fig. S3), likely underlie the increased vSTR DAT-mediated DA-uptake and resultant reduction in AMPHstimulated hyperlocomotion seen in RGS12-null-mice [40], given that these two effects are reversed by KOR-inhibition (Fig. 1).

In light of augmented $\beta$-arrestin-recruitment to activated KOR upon RGS12 over-expression (Fig. 3), we speculated that RGS12 loss reduces $\beta$-arrestin-dependent internalization and/or downregulation of $\mathrm{KOR}-\mathrm{a}$ hypothesis strongly-supported by our observation of increased vSTR, but not dSTR, KOR-binding in $\beta$-arrestin-2-knockouts (Fig. 3). In contrast, $\left[{ }^{3} \mathrm{H}\right] \mathrm{DA}$-uptake is unaffected in $\beta$-arrestin-2-knockouts (Fig. S7); as others have demonstrated that KOR-mediated increases in $\left[{ }^{3} \mathrm{H}\right] \mathrm{DA}$-uptake are sensitive to PTX [49], these findings collectively suggest that basal and KOR-stimulated DA-uptake are $\beta$-arrestin-independent 
and G-protein-dependent, respectively. Enhanced KOR-dependent $\left[{ }^{3} \mathrm{H}\right] \mathrm{DA}$-uptake in the vSTR of RGS12-null-mice (Fig. 1) is thus likely mediated by increased $G$ protein-signaling downstream of KOR (Fig. 5). Under conditions of low accumbal DA-tone, RGS12-nullmice displayed an exaggerated response to KOR antagonistmediated reductions in DA-reuptake in the NAc-core, but not dSTR (Fig. 1 \& S2), further supporting that RGS12-loss engenders hypersensitivity to the effects of KOR on DAT-function selectively in the mesolimbic DA-system. Augmented KOR-mediated G protein-signaling upon RGS12-loss is further supported by increased sensitivity of RGS12-null-mice to U50,488-induced supraspinal-analgesia (Fig. 4), considered a G protein-dependent outcome of KOR-agonism [15, 30]. Conversely, RGS12-null-mice display reduced aversion to U50,488 (Fig. 4), a behavioral outcome of KOR-activation considered to be reliant on $\beta$-arrestin-signaling $[14,28]$, consistent with observations that RGS12 over-expression augments KOR-mediated $\beta$-arrestin recruitment (Fig. 3). Together, our data demonstrate that (i) RGS12 and KOR functionally interact in the vSTR, but not dSTR, (ii) RGS12 exerts specificity for KOR over other opioid-receptors, (iii) RGS12 differentially regulates signaling cascades downstream of KOR via independent mechanisms, and (iv) RGS12 is a critical determinant of KOR-mediated behavioral outcomes.

\section{FUNDING AND DISCLOSURE}

These studies were supported in part by the WVU E.J. Van Liere Endowed Medicine Professorship (to DPS.) and K01 AA023555 (to ZAM.) JDG and SWK each acknowledge prior support from an NIH/ NIGMS Behavioral \& Biomedical Sciences training grant (T32 GM081741) and current support from NIDA predoctoral NRSA fellowships (F31 DA043331 and F30 DA044711, respectively). KTS acknowledges support from P60 AA011605 and ESC acknowledges support from a postdoctoral training slot on T32 AA007573; KMB was supported by funding from U01 AA020911 and U24 AA025475. The authors declare no competing interests.

\section{ACKNOWLEDGEMENTS}

We thank Dr. Gilad Barnea for furnishing HTLA cells for in-house Tango assays.

\section{ADDITIONAL INFORMATION}

Supplementary Information accompanies this paper at (https://doi.org/10.1038/ s41386-019-0423-7).

Publisher's note: Springer Nature remains neutral with regard to jurisdictional claims in published maps and institutional affiliations.

\section{REFERENCES}

1. Crowley NA, Kash TL. Kappa opioid receptor signaling in the brain: circuitry and implications for treatment. Prog Neuropsychopharmacol Biol Psychiatry. 2015;62:51-60.

2. Chavkin C, Koob GF. Dynorphin, dysphoria, and dependence: the stress of addiction. Neuropsychopharmacology. 2016;41:373-4.

3. Schindler AG, Messinger DI, Smith JS, Shankar H, Gustin RM, Schattauer SS, et al. Stress produces aversion and potentiates cocaine reward by releasing endogenous dynorphins in the ventral striatum to locally stimulate serotonin reuptake. J Neurosci. 2012;32:17582-96.

4. Van't Veer A, Carlezon WA Jr. Role of kappa-opioid receptors in stress and anxiety-related behavior. Psychopharmacology. 2013;229:435-52.

5. Schenk S, Partridge B, Shippenberg TS. U69593, a kappa-opioid agonist, decreases cocaine self-administration and decreases cocaine-produced drugseeking. Psychopharmacology. 1999;144:339-46.

6. Chartoff EH, Ebner SR, Sparrow A, Potter D, Baker PM, Ragozzino ME, et al. Relative timing between kappa opioid receptor activation and cocaine determines the impact on reward and dopamine release. Neuropsychopharmacology. 2016;41:989-1002.
7. Chavkin C. The therapeutic potential of kappa-opioids for treatment of pain and addiction. Neuropsychopharmacology. 2011;36:369-70.

8. Carlezon WA Jr., Krystal AD. Kappa-opioid antagonists for psychiatric disorders: from bench to clinical trials. Depress Anxiety. 2016;33:895-906.

9. Kolodny A, Courtwright DT, Hwang CS, Kreiner P, Eadie JL, Clark TW, et al. The prescription opioid and heroin crisis: a public health approach to an epidemic of addiction. Annu Rev Public Health. 2015;36:559-74.

10. Koh H. Community approaches to the opioid crisis. JAMA. 2015;314:1437-8.

11. Volkow ND, Collins FS. The role of science in addressing the opioid crisis. N Engl J Med. 2017;377:1798.

12. Kaski SW, Brooks S, Wen S, Haut MW, Siderovski DP, Berry JH, et al. Four single nucleotide polymorphisms in genes involved in neuronal signaling are associated with Opioid Use Disorder in West Virginia. J Opioid Manag. 2019;15:103-9.

13. Bohn LM, Aube J. Seeking (and finding) biased ligands of the kappa opioid receptor. ACS Med Chem Lett. 2017;8:694-700.

14. Ehrich JM, Messinger DI, Knakal CR, Kuhar JR, Schattauer SS, Bruchas MR, et al. Kappa opioid receptor-induced aversion requires p38 MAPK activation in VTA dopamine neurons. J Neurosci. 2015;35:12917-31.

15. White KL, Robinson JE, Zhu H, DiBerto JF, Polepally PR, Zjawiony JK, et al. The G protein-biased kappa-opioid receptor agonist RB-64 is analgesic with a unique spectrum of activities in vivo. J Pharm Exp Ther. 2015;352:98-109.

16. Brust TF, Morgenweck J, Kim SA, Rose JH, Locke JL, Schmid CL, et al. Biased agonists of the kappa opioid receptor suppress pain and itch without causing sedation or dysphoria. Sci Signal. 2016;9:ra117.

17. Liu JJ, Sharma K, Zangrandi L, Chen C, Humphrey SJ, Chiu YT, et al. In vivo brain GPCR signaling elucidated by phosphoproteomics. Science. 2018;360: pii: eaao4927.

18. Urban JD, Clarke WP, von Zastrow M, Nichols DE, Kobilka B, Weinstein $H$, et al. Functional selectivity and classical concepts of quantitative pharmacology. J Pharm Exp Ther. 2007;320:1-13.

19. Rankovic Z, Brust TF, Bohn LM. Biased agonism: an emerging paradigm in GPCR drug discovery. Bioorg Med Chem Lett. 2016;26:241-50.

20. Che T, Majumdar S, Zaidi SA, Ondachi P, McCorvy JD, Wang S, et al. Structure of the nanobody-stabilized active state of the kappa opioid receptor. Cell. 2018;172:55-67 e15.

21. Siderovski DP, Willard FS. The GAPs, GEFs, and GDIs of heterotrimeric G-protein alpha subunits. Int J Biol Sci. 2005;1:51-66.

22. Karkhanis A, Holleran KM, Jones SR. Dynorphin/kappa opioid receptor signaling in preclinical models of alcohol, drug, and food addiction. Int Rev Neurobiol. 2017; 136:53-88.

23. Schoffelmeer AN, Rice KC, Jacobson AE, Van Gelderen JG, Hogenboom F, Heijna $\mathrm{MH}$, et al. Mu-, delta- and kappa-opioid receptor-mediated inhibition of neurotransmitter release and adenylate cyclase activity in rat brain slices: studies with fentanyl isothiocyanate. Eur J Pharm. 1988;154:169-78.

24. Tallent M, Dichter MA, Bell Gl, Reisine T. The cloned kappa opioid receptor couples to an N-type calcium current in undifferentiated PC-12 cells. Neuroscience. 1994;63:1033-40.

25. Henry DJ, Grandy DK, Lester HA, Davidson N, Chavkin C. Kappa-opioid receptors couple to inwardly rectifying potassium channels when coexpressed by Xenopus oocytes. Mol Pharm. 1995;47:551-7.

26. McLaughlin JP, Xu M, Mackie K, Chavkin C. Phosphorylation of a carboxylterminal serine within the kappa-opioid receptor produces desensitization and internalization. J Biol Chem. 2003;278:34631-40.

27. Bruchas MR, Macey TA, Lowe JD, Chavkin C. Kappa opioid receptor activation of p38 MAPK is GRK3- and arrestin-dependent in neurons and astrocytes. J Biol Chem. 2006:281:18081-9.

28. Chavkin C, Schattauer SS, Levin JR. Arrestin-mediated activation of p38 MAPK: molecular mechanisms and behavioral consequences. Handb Exp Pharm. 2014;219:281-292.

29. Hernandez A, Soto-Moyano R, Mestre C, Eschalier A, Pelissier T, Paeile C, et al. Intrathecal pertussis toxin but not cyclic AMP blocks kappa opioid-induced antinociception in rat. Int J Neurosci. 1995;81:193-7.

30. Schattauer SS, Kuhar JR, Song A, Chavkin C. Nalfurafine is a G-protein biased agonist having significantly greater bias at the human than rodent form of the kappa opioid receptor. Cell Signal. 2017;32:59-65.

31. Soundararajan M, Willard FS, Kimple AJ, Turnbull AP, Ball LJ, Schoch GA, et al. Structural diversity in the RGS domain and its interaction with heterotrimeric $G$ protein alpha-subunits. Proc Natl Acad Sci USA. 2008;105:6457-62.

32. Snow BE, Hall RA, Krumins AM, Brothers GM, Bouchard D, Brothers CA, et al. GTPase activating specificity of RGS12 and binding specificity of an alternatively spliced PDZ (PSD-95/Dlg/ZO-1) domain. J Biol Chem. 1998;273:17749-55.

33. Lambert NA, Johnston CA, Cappell SD, Kuravi S, Kimple AJ, Willard FS, et al. Regulators of G-protein signaling accelerate GPCR signaling kinetics and govern 
sensitivity solely by accelerating GTPase activity. Proc Natl Acad Sci USA. 2010;107:7066-71.

34. Han MH, Renthal W, Ring RH, Rahman Z, Psifogeorgou K, Howland D, et al. Brain region specific actions of regulator of $G$ protein signaling 4 oppose morphine reward and dependence but promote analgesia. Biol Psychiatry. 2010;67:761-9.

35. Traynor J. mu-Opioid receptors and regulators of $G$ protein signaling (RGS) proteins: from a symposium on new concepts in mu-opioid pharmacology. Drug Alcohol Depend. 2012;121:173-80.

36. Anderson GR, Posokhova E, Martemyanov KA. The R7 RGS protein family: multisubunit regulators of neuronal $G$ protein signaling. Cell Biochem Biophys. 2009;54:33-46.

37. Shu FJ, Ramineni S, Hepler JR. RGS14 is a multifunctional scaffold that integrates $G$ protein and Ras/Raf MAPkinase signalling pathways. Cell Signal. 2010;22:366-76.

38. Willard MD, Willard FS, Li X, Cappell SD, Snider WD, Siderovski DP. Selective role for RGS12 as a Ras/Raf/MEK scaffold in nerve growth factor-mediated differentiation. EMBO J. 2007;26:2029-40.

39. Webb CK, McCudden CR, Willard FS, Kimple RJ, Siderovski DP, Oxford GS. D2 dopamine receptor activation of potassium channels is selectively decoupled by Galpha-specific GoLoco motif peptides. J Neurochem. 2005;92:1408-18.

40. Gross JD, Kaski SW, Schroer AB, Wix KA, Siderovski DP, Setola V. Regulator of G protein signaling-12 modulates the dopamine transporter in ventral striatum and locomotor responses to psychostimulants. J Psychopharmacol. 2018;32:191-203.

41. Chao J, Nestler EJ. Molecular neurobiology of drug addiction. Annu Rev Med. 2004;55:113-32.

42. Russo SJ, Nestler EJ. The brain reward circuitry in mood disorders. Nat Rev Neurosci. 2013;14:609-25.

43. Bruijnzeel AW. Kappa-Opioid receptor signaling and brain reward function. Brain Res Rev. 2009;62:127-46.

44. Knoll AT, Carlezon WA Jr. Dynorphin, stress, and depression. Brain Res. 2010;1314:56-73.

45. Chefer VI, Backman CM, Gigante ED, Shippenberg TS. Kappa opioid receptors on dopaminergic neurons are necessary for kappa-mediated place aversion. Neuropsychopharmacology. 2013;38:2623-31.

46. Di Chiara G, Imperato A. Opposite effects of mu and kappa opiate agonists on dopamine release in the nucleus accumbens and in the dorsal caudate of freely moving rats. J Pharm Exp Ther. 1988;244:1067-80.

47. Donzanti BA, Althaus JS, Payson MM, Von Voigtlander PF. Kappa agonistinduced reduction in dopamine release: site of action and tolerance. Res Commun Chem Pathol Pharm. 1992;78:193-210.

48. Thompson AC, Zapata A, Justice JB Jr., Vaughan RA, Sharpe LG, Shippenberg TS. Kappa-opioid receptor activation modifies dopamine uptake in the nucleus accumbens and opposes the effects of cocaine. J Neurosci. 2000;20:9333-40.

49. Kivell B, Uzelac Z, Sundaramurthy S, Rajamanickam J, Ewald A, Chefer V, et al. Salvinorin $A$ regulates dopamine transporter function via a kappa opioid receptor and ERK1/2-dependent mechanism. Neuropharmacology. 2014;86:228-40.

50. Schmidt KT, Makhijani VH, Boyt KM, Cogan ES, Pati D, Pina MM, et al. Stressinduced alterations of norepinephrine release in the bed nucleus of the Stria terminalis of Mice. ACS Chem Neurosci. 2018;10:1908-14

51. Zhou L, Stahl EL, Lovell KM, Frankowski KJ, Prisinzano TE, Aube J, et al. Characterization of kappa opioid receptor mediated, dynorphin-stimulated [35S] GTPgammaS binding in mouse striatum for the evaluation of selective KOR ligands in an endogenous setting. Neuropharmacology. 2015;99:131-41.

52. Jordan M, Schallhorn A, Wurm FM. Transfecting mammalian cells: optimization of critical parameters affecting calcium-phosphate precipitate formation. Nucleic Acids Res. 1996;24:596-601.

53. Barnea G, Strapps W, Herrada G, Berman Y, Ong J, Kloss B, et al. The genetic design of signaling cascades to record receptor activation. Proc Natl Acad Sci USA. 2008;105:64-69.

54. Allen JA, Yost JM, Setola V, Chen X, Sassano MF, Chen M, et al. Discovery of betaarrestin-biased dopamine D2 ligands for probing signal transduction pathways essential for antipsychotic efficacy. Proc Natl Acad Sci USA. 2011;108:18488-93.

55. Bohn LM, Lefkowitz RJ, Gainetdinov RR, Peppel K, Caron MG, Lin FT. Enhanced morphine analgesia in mice lacking beta-arrestin 2. Science. 1999;286:2495-8.

56. Yorgason JT, Espana RA, Jones SR. Demon voltammetry and analysis software: analysis of cocaine-induced alterations in dopamine signaling using multiple kinetic measures. J Neurosci Methods. 2011;202:158-64.

57. Threlfell S, Lalic T, Platt NJ, Jennings KA, Deisseroth K, Cragg SJ. Striatal dopamine release is triggered by synchronized activity in cholinergic interneurons. Neuron. 2012;75:58-64.

58. Melchior JR, Ferris MJ, Stuber GD, Riddle DR, Jones SR. Optogenetic versus electrical stimulation of dopamine terminals in the nucleus accumbens reveals local modulation of presynaptic release. J Neurochem. 2015;134:833-44.

59. Castellano C, Ammassari-Teule M, Libri V, Pavone F. Effects of kappa-opioid receptor agonists on locomotor activity and memory processes in mice. Pol J Pharm Pharm. 1988;40:507-13.
60. Bohn LM, Zhou L, Ho JH. Approaches to assess functional selectivity in GPCRs: evaluating $G$ protein signaling in an endogenous environment. Methods Mol Biol. 2015;1335:177-89.

61. Pan ZZ. mu-Opposing actions of the kappa-opioid receptor. Trends Pharm Sci. 1998;19:94-98.

62. Al-Hasani R, Bruchas MR. Molecular mechanisms of opioid receptor-dependent signaling and behavior. Anesthesiology. 2011;115:1363-81.

63. Sambi BS, Hains MD, Waters CM, Connell MC, Willard FS, Kimple AJ, et al. The effect of RGS12 on PDGFbeta receptor signalling to p42/p44 mitogen activated protein kinase in mammalian cells. Cell Signal. 2006;18:971-81.

64. Kimple RJ, Kimple ME, Betts L, Sondek J, Siderovski DP. Structural determinants for GoLoco-induced inhibition of nucleotide release by Galpha subunits. Nature. 2002:416:878-81.

65. Li JG, Chen C, Liu-Chen LY. Ezrin-radixin-moesin-binding phosphoprotein-50/Na $+/ \mathrm{H}+$ exchanger regulatory factor (EBP50/NHERF) blocks U50,488H-induced down-regulation of the human kappa opioid receptor by enhancing its recycling rate. J Biol Chem. 2002;277:27545-52.

66. Sora I, Takahashi N, Funada M, Ujike H, Revay RS, Donovan DM, et al. Opiate receptor knockout mice define mu receptor roles in endogenous nociceptive responses and morphine-induced analgesia. Proc Natl Acad Sci USA. 1997;94:1544-9.

67. Pasternak GW. Molecular insights into mu opioid pharmacology: from the clinic to the bench. Clin J Pain. 2010;26:S3-9.

68. Land BB, Bruchas MR, Schattauer S, Giardino WJ, Aita M, Messinger D, et al. Activation of the kappa opioid receptor in the dorsal raphe nucleus mediates the aversive effects of stress and reinstates drug seeking. Proc Natl Acad Sci USA. 2009;106:19168-73.

69. Vien TN, Gleason CA, Hays SL, McPherson RJ, Chavkin C, Juul SE. Effects of neonatal stress and morphine on kappa opioid receptor signaling. Neonatology. 2009;96:235-43.

70. Karkhanis AN, Rose JH, Weiner JL, Jones SR. Early-life social isolation stress increases kappa opioid receptor responsiveness and downregulates the dopamine system. Neuropsychopharmacology. 2016;41:2263-74.

71. Yorgason JT, Calipari ES, Ferris MJ, Karkhanis AN, Fordahl SC, Weiner JL, et al. Social isolation rearing increases dopamine uptake and psychostimulant potency in the striatum. Neuropharmacology. 2016;101:471-9.

72. Martin-McCaffrey L, Hains MD, Pritchard GA, Pajak A, Dagnino L, Siderovski DP, et al. Differential expression of regulator of G-protein signaling R12 subfamily members during mouse development. Dev Dyn. 2005;234:438-44.

73. Butko MT, Savas JN, Friedman B, Delahunty C, Ebner F, Yates JR III, et al. In vivo quantitative proteomics of somatosensory cortical synapses shows which protein levels are modulated by sensory deprivation. Proc Natl Acad Sci USA. 2013;110:E726-35.

74. Sialana FJ, Wang AL, Fazari B, Kristofova M, Smidak R, Trossbach SV, et al. Quantitative proteomics of synaptosomal fractions in a rat overexpressing human DISC1 gene indicates profound synaptic dysregulation in the dorsal striatum. Front Mol Neurosci. 2018;11:26.

75. Saunders A, Macosko EZ, Wysoker A, Goldman M, Krienen FM, de Rivera $\mathrm{H}$, et al. Molecular diversity and specializations among the cells of the adult mouse brain. Cell. 2018;174:1015-30 e1016.

76. Calipari ES, Bagot RC, Purushothaman I, Davidson TJ, Yorgason JT, Pena CJ, et al. In vivo imaging identifies temporal signature of D1 and D2 medium spiny neurons in cocaine reward. Proc Natl Acad Sci USA. 2016;113:2726-31.

77. Tejeda HA, Wu J, Kornspun AR, Pignatelli M, Kashtelyan V, Krashes MJ, et al. Pathway and cell-specific kappa-opioid receptor modulation of excitationinhibition balance differentially gates D1 and D2 accumbens neuron activity. Neuron. 2017;93:147-63.

78. Melchior JR, Jones SR. Chronic ethanol exposure increases inhibition of optically targeted phasic dopamine release in the nucleus accumbens core and medial shell ex vivo. Mol Cell Neurosci. 2017;85:93-104.

79. Mansour A, Fox CA, Akil H, Watson SJ. Opioid-receptor mRNA expression in the rat CNS: anatomical and functional implications. Trends Neurosci. 1995;18:22-29.

80. Resendez SL, Keyes PC, Day JJ, Hambro C, Austin CJ, Maina FK, et al. Dopamine and opioid systems interact within the nucleus accumbens to maintain monogamous pair bonds. Elife. 2016;5:pii: e15325.

81. Nirenberg MJ, Chan J, Pohorille A, Vaughan RA, Uhl GR, Kuhar MJ, et al. The dopamine transporter: comparative ultrastructure of dopaminergic axons in limbic and motor compartments of the nucleus accumbens. J Neurosci. 1997;17:6899-907.

82. Chen N, Reith ME. Substrates and inhibitors display different sensitivity to expression level of the dopamine transporter in heterologously expressing cells. J Neurochem. 2007;101:377-88.

83. Robinson DL, Venton BJ, Heien ML, Wightman RM. Detecting subsecond dopamine release with fast-scan cyclic voltammetry in vivo. Clin Chem. 2003:49:1763-73. 
84. Phillips PE, Hancock PJ, Stamford JA. Time window of autoreceptor-mediated inhibition of limbic and striatal dopamine release. Synapse. 2002;44:15-22.

85. McGinnis MM, Siciliano CA, Jones SR. Dopamine D3 autoreceptor inhibition enhances cocaine potency at the dopamine transporter. J Neurochem. 2016;138:821-9.

86. Bermingham DP, Blakely RD. Kinase-dependent regulation of monoamine neurotransmitter transporters. Pharm Rev. 2016;68:888-53.

87. Richardson BD, Saha K, Krout D, Cabrera E, Felts B, Henry LK, et al. Membrane potential shapes regulation of dopamine transporter trafficking at the plasma membrane. Nat Commun. 2016;7:10423.

88. Gowrishankar R, Gresch PJ, Davis GL, Katamish RM, Riele JR, Stewart AM, et al. Region-specific regulation of presynaptic dopamine homeostasis by $\mathrm{D} 2$ autoreceptors shapes the in vivo impact of the neuropsychiatric disease-associated DAT variant Val559. J Neurosci. 2018;38:5302-12.

89. Gray AM, Rawls SM, Shippenberg TS, McGinty JF. The kappa-opioid agonist, U69593, decreases acute amphetamine-evoked behaviors and calciumdependent dialysate levels of dopamine and glutamate in the ventral striatum. J Neurochem. 1999;73:1066-74.

90. Marcott PF, Gong S, Donthamsetti P, Grinnell SG, Nelson MN, Newman AH, et al. Regional heterogeneity of D2-receptor signaling in the dorsal striatum and nucleus accumbens. Neuron. 2018;98:575-87 e574.

91. Lein ES, Hawrylycz MJ, Ao N, Ayres M, Bensinger A, Bernard A, et al. Genomewide atlas of gene expression in the adult mouse brain. Nature. 2007; 445:168-76.

92. Lipp J. Possible mechanisms of morphine analgesia. Clin Neuropharmacol. 1991;14:131-47.

93. Jensen TS. Opioids in the brain: supraspinal mechanisms in pain control. Acta Anaesthesiol Scand. 1997;41:123-32.
94. Altier N, Stewart J. The role of dopamine in the nucleus accumbens in analgesia. Life Sci. 1999;65:2269-87.

95. Gear RW, Aley KO, Levine JD. Pain-induced analgesia mediated by mesolimbic reward circuits. J Neurosci. 1999;19:7175-81.

96. Hylden JL, Nahin RL, Traub RJ, Dubner R. Effects of spinal kappa-opioid receptor agonists on the responsiveness of nociceptive superficial dorsal horn neurons. Pain. 1991;44:187-93.

97. Cai X, Huang H, Kuzirian MS, Snyder LM, Matsushita M, Lee MC, et al. Generation of a KOR-Cre knockin mouse strain to study cells involved in kappa opioid signaling. Genesis. 2016;54:29-37.

98. Todd AJ. Neuronal circuitry for pain processing in the dorsal horn. Nat Rev Neurosci. 2010;11:823-36.

99. Tsai NP, Tsui YC, Pintar JE, Loh HH, Wei LN. Kappa opioid receptor contributes to EGF-stimulated neurite extension in development. Proc Natl Acad Sci USA. 2010;107:3216-21.

100. Xu M, Petraschka M, McLaughlin JP, Westenbroek RE, Caron MG, Lefkowitz RJ, et al. Neuropathic pain activates the endogenous kappa opioid system in mouse spinal cord and induces opioid receptor tolerance. J Neurosci. 2004;24:4576-84.

101. Simonin F, Valverde O, Smadja C, Slowe S, Kitchen I, Dierich A, et al. Disruption of the kappa-opioid receptor gene in mice enhances sensitivity to chemical visceral pain, impairs pharmacological actions of the selective kappa-agonist U50,488H and attenuates morphine withdrawal. EMBO J. 1998;17:886-97.

102. Shippenberg TS, Bals-Kubik R, Herz A. Examination of the neurochemical substrates mediating the motivational effects of opioids: role of the mesolimbic dopamine system and D-1 vs. D-2 dopamine receptors. J Pharm Exp Ther. 1993;265:53-59.

103. Bruchas MR, Chavkin C. Kinase cascades and ligand-directed signaling at the kappa opioid receptor. Psychopharmacology. 2010;210:137-47. 